BULLETIN Bulletin hispanique

HISPANIQUE Université Michel de Montaigne Bordeaux

$111-1 \mid 2009$

Varia

\title{
Juan Rodríguez de Pisa, letrado y humanista granadino, traductor de Pico de la Mirandola
}

Martin Biersack

\section{(2) OpenEdition}

Journals

Edición electrónica

URL: https://journals.openedition.org/bulletinhispanique/894

DOI: 10.4000/bulletinhispanique.894

ISSN: $1775-3821$

Editor

Presses universitaires de Bordeaux

Edición impresa

Fecha de publicación: 1 junio 2009

Paginación: 7-50

ISBN: 978-2-86781-586-7

ISSN: 0007-4640

Referencia electrónica

Martin Biersack, «Juan Rodríguez de Pisa, letrado y humanista granadino, traductor de Pico de la Mirandola», Bulletin hispanique [En línea], 111-1 | 2009, Publicado el 01 junio 2012, consultado el 21 septiembre 2021. URL: http://journals.openedition.org/bulletinhispanique/894 ; DOI: https://doi.org/ 10.4000/bulletinhispanique.894 


\title{
Juan Rodríguez de Pisa, letrado y humanista granadino, traductor de Pico de la Mirandola
}

\author{
Martin Biersack \\ Université de Regensburg - Allemagne
}

Juan Rodríguez de Pisa est l'auteur de la Curia Pisana, le premier traité d'administration des villes castillanes. Il est aussi le premier à traduire en espagnol un texte de Pic de la Mirandole. L'objet de cet article est de reconstruire la biographie de Juan Rodriguez, de commenter les premières réactions provoquées en Espagne par l'ouvrage de Pic de la Mirandole et d'analyser la traduction des Duodecim regulae.

Juan Rodríguez de Pisa fue autor de la Curia Pisana, el primer tratado sobre el gobierno de las ciudades castellanas, asi como el primer traductor al castellano de una obra de Giovanni Pico de la Mirandola. El propósito de este artículo es reconstruir la biografia de Juan Rodríguez de Pisa, ofrecer algunos comentarios sobre las primeras reacciones que causó la obra de Pico de la Mirandola en España, y analizar la traducción de las Duodecim regulae.

Juan Rodríguez de Pisa is the author of "Curia Pisana", the first treaty dealing with how to run Castilian towns. He was also the first to translate into Spanish one of Pic de la Mirandole's texts. This article aims at reconstructing a biography of Juan Rodriguez's, at commenting upon the first reactions to Pic de la Mirandole's work in Spain, as well as at presenting an analysis of the translation of the "Duodecim Regulae».

Mots-clés : Humanisme - Pic de la Mirandole - Spiritualité - Convers Traduction.

$B H i$, Tome 111, n $^{\circ} 1$ - juin 2009 - p. 7 à 50. 


\section{BiOgRAFÍA}

乙oy en día, Juan Rodríguez de Pisa nos es conocido principalmente por dos circunstancias: por un lado, por haber sido el autor de la Curia Pisana, el primer tratado castellano sobre el gobierno municipal, y, por otro, por ser el fundador de la Casa de los Pisa en Granada, donde el día ocho de marzo de 1550 murió San Juan de Dios. Andrés Vázquez Cano, en un artículo publicado a principios del siglo XX sobre la familia de los Pisa, fue el primero en llamar la atención sobre el personaje de Juan Rodríguez de Pisa. Vázquez Cano aprovechó el hallazgo del legajo de un pleito decimonónico en la Real Cancillería de Granada para reconstruir la genealogía de los Pisa, empezando por el padre de Juan Rodríguez hasta llegar a Luisa Castelli, Grande de España y vecina de Milán ${ }^{1}$. Recientemente, José Antonio López Nevot publicó un estudio sobre la Curia Pisana, precedido por una biografía sobre Juan Rodríguez de Pisa -que va a ser la primera, y hasta ahora, única sobre el jurista. Aparte del trabajo de Vázquez Cano y de la información contenida en la Curia Pisana, López Nevot basa su estudio en documentos obtenidos del Archivo Histórico Municipal de Granada ${ }^{2}$. No obstante, este autor no pudo encontrar el pleito de la Real Cancillería granadina en el que Vázquez Cano basó su trabajo, alegando que «desafortunadamente, este autor [Vázquez Cano] no cita la procedencia de los datos que recopila [...]» $»^{3}$. El presente artículo tiene como objetivo arrojar más datos sobre la vida de Juan Rodríguez de Pisa, sobre su ascendencia conversa, sus actividades en la Corte Real y en Granada, y, sobre todo, presentarle como el traductor de un opúsculo de Giovanni Pico de la Mirandola, las Doze Reglas, con la que el letrado granadino debería ser considerado como el primer traductor del gran filósofo italiano en España.

Los Pisa eran oriundos de Almagro. La progenie judeoconversa de Juan Rodríguez de Pisa consta en un documento procedente de una visita hecha a la Real Cancillería de Ciudad Real, según el cual el Alcalde de Hijosdalgo, el licenciado Juan de Pisa, era hijo de un reconciliado y nieto de un penitenciado ${ }^{4}$. López Nevot no erró al relacionar al licenciado Juan de Pisa

1. A. Vázquez Cano, "Los Pissa», Revista del Centro de Estudios Históricos de Granada y su Reino, 4, 1911, p. 157-170. El pleito con ejecutoria del año 1848 se encuentra en RCG, leg. 9082, p. 001.

2. J. A. López Nevot, "De Curia Pisana. Literatura jurídica y regidores municipales», Historia de la literatura jurídica en la España del Antiguo Régimen. Ed.: J. Alvarado, vol. I, Madrid, 2000, p. 473-498.

3. López Nevot, "De Curia Pisana...", p. 475.

4. S. M. Coronas González, «La Audiencia y Cancillería de Ciudad Real (1494-1505)», Cuadernos de Estudios Manchegos, 11, 1981, p. 46-139, p. 118. 
con nuestro Juan Rodríguez de Pisa ${ }^{5}$, como demostrarán dos genealogías de la Real Academia de la Historia y un documento de Simancas. El padre de Pisa era un rico mercader llamado García de Pisa ${ }^{6}$ y estaba casado, según el pleito de la Real Cancillería, con María Sánchez ${ }^{7}$. Tuvieron ocho hijos: Andrés de Pisa, regidor de Almagro; el licenciado y protonotario Alonso de Pisa el Romano; María Rodríguez de Pisa, mujer de Alonso Gutiérrez de la Caballería; Aldonza Rodríguez de Pisa, mujer de Fernando de Villareal ${ }^{8}$; Juana de Pisa, casada con Marcos de Madrid; Teresa de Pisa, mujer de Francisco de Palacios; Isabel de Pisa, mujer de Alonso Fernández de Villafelices y, por último, Catalina de Pisa, mujer de Rodrigo de la Sierra ${ }^{9}$.

Según una genealogía de la Real Academia de la Historia, el abuelo de Juan Rodríguez de Pisa se llamaba Miguel de Pisa y estaba casado con María de Deza ${ }^{10}$. No obstante, no será éste el que fue sentenciado por la Inquisición, ya que, según una Habilitación Real, el abuelo de nuestro licenciado que cayó en las manos de la Inquisición se llamaba como su nieto: Juan Rodríguez de Pisa $^{11}$. Era natural de Almagro y fue, junto con un hijo suyo, Fernando, condenado por la inquisición de Toledo ${ }^{12}$. Pero ipor qué, entonces, en una genealogía de la Real Academia le mencionan como «Miguel de Pisa»? Tal vez responda a un error del genealogista, o bien los dos abuelos de Juan

5. López Nevot, «De Curia Pisana...», p. 476.

6. V. Parello, Les Judéo-Convers. Tolède $X V$-XVI' siècles. De l'exclusion à l'intégration, Paris, 1999, p. 152.

7. En una genealogía de la familia de los Pisa que se halla en la Real Academia de la Historia, la madre de Pisa lleva el nombre María Díaz Agujetas. Véase RAH, Col. Salazar, 9-146 Bis., fol. 177r.

8. Fernando de Villareal pertenecía a la planta administrativa de la Hermandad. Véase: M. Lunefeld, The Council of the Santa Hermandad. A study of the pacification forces of Ferdinand and Isabella, Miami, 1970, p. 63. En 1495 actuaron un tal Fernando de Villareal y un tal García de Pisa juntos como recaudadores de diezmos de las Alpujarras. ¿Podría tratarse de suegro y yerno? A. García Pedraza, «La prosopografía de los intermediarios fiscales del Reino de Granada (1492-1515). Una historia por hacer», Chronica Nova 31, 2005, p. 147-195, p. 165.

9. Vázquez Cano, «Los Pissa», p. 24. Las hermanas de Juan Rodríguez de Pisa se casaron por lo tanto con miembros de familias conversas. Marcos de Madrid, la familia de los Caballería y la familia Villareal por lo menos eran de esta procedencia. La práctica de alianzas matrimoniales era muy habitual entre conversos y también practicada por los Pisa. Véase: Vincent Parello, Les Judéo-Convers, p. 153-160. También la familia de la Sierra era perseguida por la Inquisición. Véase: H. Beinhart, «Records of the Inquisition. A Source of Jewish and Converso History», Proceedings of the Israel Academy of Sciences and Humanities, 11, vol. 2, p. 211-227, p. 220.

10. RAH, Col. Salazar, 9-309, fol. 193v.

11. AGS, CCA-CED, 5, 328, 1. Véase nota 18.

12. RAH, Col. Salazar, M-99, fol. 196r, y también Col. Salazar, 37-4, n. 4. 
Rodríguez, tanto el materno como el paterno, procedían de la familia de los Pisa y uno se llamaba Juan Rodríguez y el otro Miguel. De lo que no tenemos duda es del origen converso de Juan Rodríguez de Pisa. Todavía en 1658 el apellido de Pisa causaría problemas a Pedro de Alarcón y Zúñiga de Contreras al querer entrar en la orden de Santiago por ser su abuela paterna Elvira de Pisa, nacida en Almagro y nieta de García de Pisa ${ }^{13}$.

La primera vez que Juan Rodríguez de Pisa aparece en la historia es el dia cinco de septiembre de 1498, cuando los Reyes Católicos le dan una orden de emplazamiento junto con Fernando de Albelda, como él, vecino de Almagro. Ambos habían sido comisionados por el tesorero general de la Hermandad, Alonso Gutiérrez de Madrid, para pagar a la gente de la Hermandad en el Reino de Granada y ahora eran llamados para rendir cuentas sobre su gestión ante los licenciados Francisco de Malpartida y de Pedrosa ${ }^{14}$. Es probable que el ser cuñado de uno de los administradores de la Hermandad, Fernando de Villareal, ayudase al entonces joven Juan a entrar en el servicio de la Hermandad.

Nada sabemos sobre la formación académica de Juan Rodríguez, ni dónde ni cuándo consiguió el grado de licenciado. Probablemente estuvo en Bolonia, porque en su De Curia Pisana no solamente cita la inscripción que está colocada a la entrada del palacio pontificio, sino que también describe la estatua de un juez con una balanza en sus manos:

Et in palatio pontificis maximi qui est bononie in tribunali stat praetor in manibus gestans staterant. Et sunt descripti hic versus: vos regentes obliti privatorum publica curate $[\ldots]^{15}$.

Si aceptamos que Pisa observó en persona esta inscripción, entonces sería más que probable que se encontrase allí para cursar sus estudios en Derecho. Su excelente carrera jurídica y su profundo conocimiento del humanismo italiano hacen probable esta hipótesis.

En fecha desconocida para nosotros entró en la Real Cancillería de Ciudad Real donde en 1501 lo encontramos desempeńando el oficio de Alcalde de Hijosdalgo ${ }^{16}$, y donde su origen judío no pasaría desapercibido, causándole los consiguientes problemas. El visitador de la Cancillería, Martín de Córdoba, le reprocharía no sólo su falta de hidalguía para llevar tal oficio

13. J. Pérez Balsera, Los caballeros de Santiago, vol. 2, Madrid, 1933, p. 240 y 243.

14. AGS, RGS, fol. 271.

15. Juan Rodríguez de Pisa, De Curia Pisana [Medina del Campo] 1532, BNE, R/31012, fol 8 r.

16. Coronas González, La Audiencia y Cancillería de Ciudad Real, p. 110-139 y 77-78. 
sino también su ascendencia judía. Tanto la hidalguía como la limpieza de sangre eran obligatorias, especialmente esta última, ya que a partir de 1501, los descendientes de condenados por herejía quedaron excluidos de ejercer oficios hasta la segunda generación por vía masculina ${ }^{17}$. No obstante, Juan Rodríguez de Pisa supo evitar los problemas que su ascendencia le causaba presentando una Real Cédula de Habilitación de los Reyes Católicos por la que se le facultaba para ejercer el oficio de abogado ${ }^{18}$.

Nos es desconocida la fecha en la que llegó a Granada, aunque lo más probable es que lo hiciese con el traslado de la Real Cancillería en 1505 de Ciudad Real a Granada. En 1513 dejó constancia en el epistolario del II Conde de Tendilla, Iñigo López de Mendoza. La primera mención que don Iñigo hace de él es del mes de abril, cuando Pisa fue requerido por el Conde de Ureña para asesorarle en una negociación con la Corte ${ }^{19}$. Probablemente se trata del levantamiento de Pedro Girón, hijo del conde de Ureńa, por la herencia del ducado de Medina Sidonia. En julio, Pisa formó parte de un enfrentamiento entre la Real Cancillería y la Capitanía General ya que peones de la Alhambra habían golpeado a un sastre por incumplimiento de los plazos acordados. Ińigo López de Mendoza, Capitán General del Reino de Granada y, también, Alcalde de la Alhambra ofreció protección a sus soldados, hecho que provocaría la protesta de la Real Cancillería, que amenazó al conde con una multa de 10.000 castellanos de oro. Uno de los representantes de la Cancillería fue Juan Rodríguez de Pisa, quien, junto con otros letrados del tribunal, intentó, después del primer enfrentamiento, calmar los ánimos y llevar el asunto a buen término, aconsejando al conde una apelación ${ }^{20}$.

Como otros miembros de la familia de los Pisa, también el licenciado Juan Rodríguez seguiría la pauta de muchos otros conversos que empezaron una carrera en la administración municipal o real ${ }^{21}$. El día 1 de julio de

17. López Nevot, «De Curia Pisana...», p. 476 y nota 14.

18. La Real Cédula iba dirigida al licenciado Juan Rodríguez de Pisa, vecino de Ciudad Real diciendo que «[...] por haber sido Juan Rodríguez de Pisa vuestro aguelo condenado por el delito de herejia [...] no podeis usar oficio de abogado sin nuestra licencia [...]" y dandole en lo siguiente tal licencia. Fecha en Sevilla, 1.3. 1501. AGS, CCA-CED,5,328,1.

19. Carta del 26. de abril de 1513 a Diego de Guzmán, en: Correspondencia del conde de Tendilla, Biografía, estudio y transcripción por Emilio Meneses García, vol. 2, Madrid, 1973, p. 283.

20. Carta del 15 de julio de 1513 del Conde de Tendilla al licenciado Vargas, en: Correspondencia del conde de Tendilla, vol. 2, p. 452; véase también: J. Szmolka Clares, El Conde de Tendilla: primer capitán general de Granada, Granada, 1981, p. 146.

21. Sobre los conversos en la administración municipal en general véase: Parello, Les JudéoConvers, p. 164-170; sobre la rama de los Pisa en Almagro y en Cuenca en especial y su éxito 
1516 consta el nombramiento de Juan Rodríguez de Pisa como letrado del Cabildo $^{22}$. El 25 de octubre del mismo año obtuvo el título de regidor ${ }^{23}$, gracias a las recomendaciones que el nuevo Capitán general, el joven Luis Hurtado de Mendoza, le había hecho en la Corte ${ }^{24}$. La acumulación de cargos por parte de Rodríguez de Pisa causó en 1517 la protesta de otro regidor, el doctor Méndez de Salazar, y, al no surtir ésta efecto, dos años más tarde la de otros jurados ${ }^{25}$. En enero de 1517 se mudó a Madrid, donde, durante la regencia de Cisneros, residió la Corte ${ }^{26}$. Desconocemos qué tipo de negocios lo llevaron allí, aunque es posible que respondiese a un encargo de la Ciudad. Quizás Pisa negociara en la Corte sobre los daños producidos por el inquisidor Lucero en Granada y la restitución de los bienes a sus víctimas -asunto que la ciudad de Córdoba llevaba a cabo y al que se sumó Granada ${ }^{27}$.

Tenemos constancia de su actividad en Granada a partir de su ingreso en el Cabildo. Una parte importante de estas actividades estuvieron dedicadas a la enseñanza, como se verá luego en el capítulo sobre Juan Rodríguez de Pisa, el humanista. Pisa estuvo también implicado en el pleito entre el Consejo de la Ciudad y la Capilla Real por la construcción del edificio de la Lonja. Cuando la Ciudad empezó con las obras de la Lonja, los capellanes de la Capilla Real, vecina directa de la Lonja, protestaron contra tal propósito. El asunto llegó a manos de la Real Cancillería y las obras quedaron paralizadas. No obstante, el Consejo decidió seguir adelante con las mismas, sin esperar una sentencia afirmativa. Contra esta medida protestó el licenciado de Pisa alegando la falta de facultades regias para llevar a cabo la obra ${ }^{28}$. Parece ser

en la administración municipal la p. 168. del mismo autor. Un homónimo de nuestro Juan Rodríguez de Pisa, hijo del jurista Manuel de Pisa, era regidor de Cuenca y Almagro.

22. J. Antonio López Nevot, La organización institucional del municipio de Granada durante el siglo XVI (1492-1598), Granada, 1994, p. 294, n. 434.

23. El nombramiento real y la admisión de Pisa por parte del Cabildo granadino el 7.11.1516 fue publicado por López Nevot, «De Curia Pisana...», p. 495-498.

24. BNE, Ms 10231, Registro de cartas de D. Ińigo López de Mendoza, Conde de Tendilla, sobre el gobierno de las Alpujarras, fol. 100r.

25. AHMG, Libro de Actas III, sesión del 22 de mayo de 1517, fol. 142r y AHMG, Libro de Actas IV, Sesión del 18. de enero de 1519, fol. 50r. Citados por López Nevot, «De Curia Pisana...», p. 477-478.

26. J. Martínez Millán (Ed.), La corte de Carlos V, vol. I. Corte y gobierno, Madrid, 2000, p. 142.

27. Cartas del II marqués de Mondéjar a Pisa del 20.1.1517 y del 13.2.1517. BNE, Registro de cartas, fols. 136r y 143 r.

28. R. López Guzmán, Tradición y Clacisismo en la Granada del siglo XVI, Granada 1987, p. 530. 
que Pisa cumpliría aquí con una de sus máximas: decir siempre la verdad tal y como la sentía, sin ser parcial: "Dicam veritatem quam sentio» ${ }^{29}$.

Pisa también tomó parte en las disputas entre regidores y jurados por el gobierno de la ciudad y en fecha desconocida hizo algunas alegaciones a favor de los primeros y en contra de los jurados ${ }^{30}$. El debate entre regidores y jurados en el cabildo granadino consta en un discurso hecho por el humanista Hernán Núñez de Toledo, el día 5 de noviembre de 1512. En dicho discurso, Hernán Núñez defendía el derecho de los jurados de poder participar en los procedimientos jurídicos del cabildo. Esta posición era respaldada por el marqués de Mondéjar y su partido. La oposición estaba formada por todos aquellos que querían restar importancia al papel desempeñado por los jurados: los letrados de la Cancillería, los tesoreros reales y los notarios ${ }^{31}$. Debemos suponer que, por aquellas fechas, Pisa formuló sus alegaciones para apoyar la posición del segundo grupo.

En 1523, tanto Juan Rodríguez de Pisa como Hernando Álvarez de Zapata, representarían a Granada en las Cortes de Valladolid. Allí Pisa llamaría la atención al exigir del Emperador, en su nombre y en el de todos los procuradores, el cumplimiento de los capítulos presentados por los procuradores antes de votar el servicio, que éste había solicitado. Carlos $\mathrm{V}$ respondió, en un desenfadado discurso, con bastante vehemencia a este atrevimiento por parte del procurador granadino, aunque siguió exigiendo la votación del servicio antes de hablar sobre los capítulos, prevaleciendo, finalmente, después de varias reuniones, la voluntad real ${ }^{32}$.

A pesar de este enfrentamiento con el Emperador, Juan Rodríguez de Pisa pudo comenzar una carrera en la Corte. En 1524 participó como abogado, nombrado por el Emperador, en la Junta de Badajoz, donde portugueses y españoles debatían en vano sobre la posesión de las Malucas ${ }^{33}$. Es probable que también perteneciese al Consejo Real. En un documento de obligación de 1525 que le convertía en tutor de las tres hijas del marqués del Cenete, Pisa ya llevaba el título "del Consejo» ${ }^{34}$. No obstante, López Nevot supone

29. Pisa, De Curia Pisana, fol. 40r.

30. «[...] feci quasdam allegationes in favorem Decurionem et contra juratos Granate». Pisa, Curia Pisana, fol. 40r.

31. H. Nader, «The greek Commander Hernán Núñez de Toledo, Spanish Humanist and Civic Leader», Renaissance Quaterly, 31, 1978, p. 463-485, p. 477-480.

32. M. Fernández Álvarez, La España del Emperador Carlos V (1500-1558; 1517-1666). Historia de España, vol. 20. Ed.: R. Menéndez Pidal, Madrid 1966, p. $225 \mathrm{ff}$.

33. Francisco López de Gómara, Historia General de las Indias, Zaragoza 1554, cap. C. Sobre la Junta de Badajoz y el papel de Pisa en las negociaciones véase: E. H. Blair, The Philippine Islands. 1493-1803, vol. 1, Cleveland, 1965.

34. AHN, Osuna, C. 1769, D. 10. 
que la titulación «del nuestro Consejo» con la que le trata también la reina en la licencia de impresión de la Curia Pisana, es solamente honorífica ${ }^{35}$. Oidores de las Audiencias y también los Alcaldes de Casa y Corte solían llevar este título sin pertenecer realmente al Consejo Real ${ }^{36}$. El genealogista de los Pisa nos proporciona una pista más y alega que Pisa «no quiso Placa del Consejo que le dava el emperador ${ }^{37}$. Pisa estuvo en la Corte del Emperador, desempeñando allí el oficio de abogado. No obstante, puede que no quisiera integrarse formalmente en el Consejo Real, tal y como pedía el Emperador -o, si lo hizo, lo dejara al poco tiempo- y prefiriese regresar a Granada para desempeñar el oficio de Oidor en la Real Cancillería, cargo que igualmente le permitía llevar el título de "Consejero Real».

El mismo genealogista le hace también «auctor de que instituyese la Apelacion de las 1500 Doblas» ${ }^{38}$. Con esta apelación se podía, en asuntos de cierta gravedad, ir ante el rey como segundo recurso. La justicia exigía de los apelantes el depósito de una fianza de 1500 doblas, que perdían en el caso de confirmarse la anterior sentencia. Esta apelación existía ya antes de los Reyes Católicos, siendo establecida por primera vez en las Cortes de Segovia en 1390, confirmada por las Cortes de Toledo de 1480 y denominada por vez primera en 1489 "suplicación de la mill y quinientas doblas» ${ }^{39}$. Por cuestión de edad, es difícil que Pisa fuese el responsable de la institución de la apelación de las 1500 doblas en los años ochenta del siglo XV. En el caso de que lo hubiese sido, cabría suponer que estuviese a los órdenes del jurista Pedro Díaz de Montalvo ${ }^{40}$. Parece más probable que tuviese algo que ver con la reforma de esta apelación en las leyes para abreviar pleitos en torno al año 1500. El problema al que, en general, la apelación de las 1500 doblas quería hacer frente, era la desmesurada ocupación del Consejo Real con pleitos. Hernando de Pulgar comentó este hecho con las siguientes palabras:

Otrosí, porque en la corte se trataban muchos pleitos e causas ante los del consejo, los cuales eran tantos e de tantas

35. López Nevot, «De Curia Pisana...», p. 479.

36. S. de Dios, El Consejo Real de Castilla (1385-1522), Madrid, 1982, p. 263-266.

37. RAH, Col. Salazar: 9 - 146 Bis, fol. 177 r.

38. RAH, Col. Salazar: 9 - 146 Bis, fol. 177r.

39. J. Sánchez-Arcilla Herual, La administración de justicia real en León y Castilla (12521504), Madrid, 1980, p. 529.

40. Pero Díaz de Montalvo era converso y de Cuenca. La proximidad geográfica, la común descendencia de conversos y la profesión de juristas hace posible una cierta familiaridad entre él y Pisa aunque no la he podido confirmar en ningún documento. 
calidades, que impedían a los del consejo que no pudiesen entender en las cosas que ocurrían e avian de librar por expediente $[\ldots]^{41}$.

En una ordenanza del 21 de mayo de 1499 se excluía al Consejo Real del procedimiento de la segunda apelación. A partir de ahora, en el caso de una segunda apelación, para la cual había que depositar una fianza de 1500 doblas, ésta se realizaría ante las dos audiencias, en lugar de apelar ante el Consejo. Pero ya el 10 de marzo de 1501 una Real Cédula revocó tal procedimiento y determinó que las segundas apelaciones fueran realizadas otra vez directamente a la Corte para que los Reyes las sometieran a jueces aptos. Esta práctica entraría finalmente en las leyes con el fin de abreviar los pleitos de $1502^{42}$. Sin embargo, con el tiempo, se fue generando la costumbre de no entregarse las segundas apelaciones a otros «jueces aptos» sino al Consejo Real, donde se constituyó una Sala de las Mil y Quinientas ${ }^{43}$ para tales apelaciones. Si Pisa estuvo realmente implicado en esta reforma jurisdiccional, es probable que ya en estas fechas estuviera ligado a la corte de los Reyes Católicos y al Consejo Real.

Otra posible colaboración de Pisa en la reforma de la apelación de las 1500 podría haberse dado en tiempos del Emperador, cuando se subió el depósito de 1500 a 4000 doblas, exigiéndose esta cantidad a los litigantes para poder apelar en la Sala de Mil y Quinientas. La razón del desmesurado aumento del depósito era que el Consejo real, en vez de ser un instrumento plenamente gubernamental, intervenía demasiado en asuntos jurídicos. Los consejeros, conscientes del prestigio y de las oportunidades de corrupción e influencia que ofrecían los pleitos, intentaron extraer causas importantes de las Audiencias, saltándose así el procedimiento ordinario. Al igual que la instalación de las 1500 doblas, la subida del depósito a 4000 doblas fue un intento, por parte de la Corona, de reducir el número de pleitos en el Consejo. Richard L. Kagan cita un aviso, dado en 1525 por un secretario o consejero anónimo al emperador sobre la función del Consejo Real:

41. Hernando de Pulgar, Crónica de los Reyes Católicos, vol. 2. Ed.: J. de Mata Carriazo, Madrid, 1942, cap. 181, p. 205.

42. Sobre la apelación de las 1500 doblas véase: Dios, Consejo Real, p. 412; I. Czeguhn, Die kastilische Höchstgerichtsbarkeit 1250-1520, Berlin, 2002, p. 107; G. Villapalos Salas, Los recursos contra los actos de gobierno en la Baja Edad Media. Su evolución histórica en el reino castellano. 1254-1504, Madrid, 1976; J. Sánchez-Arcilla Herual, La administración de justicia, p. 529-530.

43. Dios, Consejo Real, p. 412. 
Determinen con mucha diligencia las residencias y visitaciones de vuestras audiencias, corregimientos, y de todos los otro oficiales de justicia del Reyno [...] pues este es su proprio oficio del consejo y entender en la buena provision y gobernacion de las cosas del Reyno y no ocupar el tiempo en pleitos ordinarios entre partes porque para estos V. M. tiene sus audiencias donde sean de determinar segun ley y razon y de traerlos al consejo allende de los grandes inconvenientes y dilacion y gastos que se sigue a las partes de ocuparse en el oficio que no es suyo y perder tiempo en el, no pueden entender en la gobernacion del Reyno ${ }^{44}$.

Kagan supone que fue, quizás, Francisco de los Cobos quien escribió estas líneas pero podría haber sido también Pisa. Ya en las Cortes de Valladolid de 1523 los procuradores de las ciudades, y entre ellos Juan Rodríguez de Pisa, pidieron al Emperador que no se vieran más los pleitos de las audiencias en el Consejo ${ }^{45}$.

Aparte de sus oficios en la Real Cancillería, en el Consejo municipal de Granada y en la Corte Real, Juan Rodríguez de Pisa trabajó como abogado de la nobleza asentada en el antiguo Reino granadino. En 1513 fue llamado para asesorar al conde de Ureña, como ya ha sido mencionado anteriormente. El II marqués de Mondéjar le pidió en 1517 que recibiera a su agente en la Corte, Francisco Ortiz, y que le aconsejara «en lo que ha de haçer» acerca de los negocios del marqués. De dicha petición podemos extraer que Pisa poseía bastante experiencia en lo referente a los trámites y el funcionamiento de la Corte, ya que Ortiz, para nada era un principiante en la Corte, siendo ya desde hacía años el agente de su padre ${ }^{46}$. En 1518 doña Elvira Fernández de Córdoba, Duquesa de Sessa e hija del Gran Capitán requirió los servicios del jurista para su matrimonio con Luis Fernández de Córdoba ${ }^{47}$. En 1525 sería nombrado tutor de las hijas del marqués del Cenete, Mencía, Catalina

44. AGS, Estado, leg. 15, part. 2, fol. 20. Citado por R. L. Kagan, Pleitos y pleiteantes en Castilla, 1500-1700, Valladolid, 1991, p. 128.

45. Colección de Cortes de los antiguos reinos de León y de Castilla, vol. 4. Ed.: Real Academia de la Historia, p. 387-388.

46. Carta de Mondéjar a Pisa del 20.1.1517. BNE, Registro de cartas, fol. 136r.

47. AHN, Sección Nobleza, Baena,C.23,D.18. «Carta de poder otorgada por María Manrique, [I] Duquesa de Terranova, y su hija Elvira [Fernández] de Córdoba [Manrique], [II] Duquesa de Sessa, a favor del licenciado Juan Rodríguez de Pisa, veinticuatro de Granada, para que pueda otorgar las escrituras y obligaciones necesarias para el cumplimento de lo tratado en el matrimonio de la citada Duquesa de Sessa con Luis [Fernández] de Córdoba [Zúñiga], hijo de Diego Fernández de Córdoba [Hurtado de Mendoza], [III] Conde de Cabra y [v] Señor de la Villa de Baena». 
y María, sucediendo en este cargo a Diego Hurtado de Mendoza, quién después de la muerte de don Rodrigo de Mendoza había sido nombrado tutor de las tres hijas de su hermano. Don Diego, sin embargo, pidió al emperador que nombrara un tutor particular para los dominios castellanos de las nobles damas. La elección recayó en Juan Rodríguez de Pisa, quien se convirtió así en tutor y administrador de los bienes castellanos de las tres hijas del marqués. En Toledo le fueron entregados los bienes de dońa Catalina y doña María, dejando Pisa constancia de este hecho con la elaboración de un inventario ${ }^{48}$. Más tarde encontramos a Pisa defendiendo a los marqueses del Cenete en un pleito que tenían en la Corte contra Antonio de Fonseca. Esta ayuda que el licenciado prestó a los marqueses no le resultó en vano ya que, gracias a la intervención del marqués del Cenete, Enrique de Nassau ante el emperador, Pisa sería nombrado Oidor en la Real Cancillería de Granada. Este hecho provocó la protesta de Antonio de Fonseca, quien no solamente vio en perjuicio su causa por el galardonado real del abogado de su enemigo, quejándose, además, del daño causado al bien común del reino por la ayuda que Pisa prestaba al Marqués del Cenete en la Corte, al cobrar, al mismo tiempo, el salario de Oidor de la Real Cancillería ${ }^{49}$. Desconocemos la fecha del nombramiento de Pisa como Oidor. Lo más probable es que se tratara del año 1525, ya que en este año fueron ocupados los puestos por dos Oidores, cuya creación se había acordado ya en 1522 después de la visita a la Chancillería de Francisco de Herrera ${ }^{50}$. Hasta 1525 Pisa no aparece en las nóminas de la Real Cancillería de Granada, como señalan Ángel Galán Sánchez y Rafael G. Peinado Santaella en su estudio sobre el personal de la Real Cancillería basado en el análisis de las cuentas de la Contaduría Mayor de los Reyes Católicos ${ }^{51}$. Este hecho hace suponer que Pisa ejercía, por lo menos hasta el año 1525, el oficio de Alcalde de Hijosdalgo ya que este cargo no dependía de las arcas reales. Los alcaldes cobraban sus derechos directamente de los pleitantes y, por lo tanto, no dejaron huella en las cuentas de la Contaduría Mayor.

Parece ser que Juan Rodríguez de Pisa fue un abogado de extraordinarias cualidades. Sus servicios fueron requeridos, no solamente por

48. AHN, Sección Nobleza, Osuna, C. 1769, D.10.

49. Carta fechada en Madrid a 19 de julio, dirigida por Antonio de Fonseca al emperador. Según una disposición bajomedieval se prohibía a los oidores y alcaldes ejercer la abogacia. Véase: López Nevot, "De Curia Pisana...", p. 479 y p. 480, nota 34.

50. Czeguhn, Die kastilische Höchstgerichtsbarkeit, p. 121.

51. A. Galán Sánchez, R. G. Peinado Santaella, «Los jueces del rey y el coste de la justicia: prosopografía y presupuesto de la Real Cancillería de Granada (1505-1525)». En: Tomás Quesada Quesada. Homenaje, Granada 1998, p. 271-295, p. 272 y n. 4 
el Ayuntamiento de Granada y destacados miembros de la nobleza -los duques de Sessa, los marqueses de Mondéjar y Cenete y el conde de Ureña- sino también por el propio emperador, al nombrar a Pisa su abogado en la Junta de Badajoz. No es en balde, por lo tanto, que el ya citado genealogista le llame «famoso abogado en tiempo del emperador» ${ }^{52}$.

La relación de Pisa con los duques de Sessa y con los marqueses del Cenete resulta bastante sospechosa, al ser éstos justo los nobles que formaron la oposición más dura contra el régimen del Capitán General en la ciudad nazarí. ¿Pertenecía Juan Rodríguez de Pisa por lo tanto a la oposición contra los marqueses de Mondéjar? Primero hay que pensar en la tradicional oposición entre la Real Cancillería y la Capitanía General en la pugna por el control gubernamental de Granada. Desde la instalación de la Audiencia en Granada las tensiones entre los dos cuerpos no cesaron ${ }^{53}$. Uno de los primeros incidentes documentados es el ya mencionado conflicto por la jurisdicción sobre unos soldados delincuentes del primer Capitán General, Iñigo López de Mendoza, en 1513. En este conflicto, Pisa pertenecía al grupo de los letrados de la Cancillería que querían tratar con mano dura a los soldados y a su protector, amenazándolos con duras penas. No obstante, posteriormente moderaría su actitud, mostrándose reconciliador con el Capitán general, alegando que «vistas las provisiones» del conde le «hazian gran sin razon» ${ }^{54}$.

Es también sospechoso, que en las Cortes de Valladolid, donde Pisa estuvo presente como procurador de Granada, pidiesen al emperador que excluyera a «las personas de titulo y grandes señores» de las regidurías y otros oficios municipales "porque por la espiriencia se muestra quanto es deserviçio de vuestra Alteza y daño e ynconviniente de los tales pueblos" ${ }^{55}$. En el caso de Granada, esto significaba un claro ataque a los intereses de los Mondéjar en el control del municipio. Hay que tener presente que varios miembros de esta familia llevaban regidurías en Granada, como el propio don Luis desde 1506 y su hermano Antonio de Mendoza desde $1513^{56}$. El licenciado arremetiría también contra el grupo de los jurados, protegidos por los marqueses de Mondéjar, proponiendo su exclusión del cabildo.

52. RAH, Col. Sal.9 - 146 Bis, fol. 177r.

53. Véase: A. Jiménez Estrella, Poder, Ejército y Gobierno en el siglo XVI. La Capitanía general del Reino de Granada y sus Agentes, Granada, 2004, p. 48-51.

54. Carta del 15. de julio de 1513 al licenciado Vargas, en: Correspondencia del conde de Tendilla, vol. 2, p. 453.

55. Cortes de los antiguos reinos de León y de Castilla, vol. 4, p. 374, citado por López Nevot, "De Curia Pisana...», p. 487.

56. Jiménez Estrella, Poder, ejército y gobierno en el siglo XVI, p. 286. 
Conocido es el empeño que el primer marqués del Cenete, Rodrigo de Mendoza, puso en formar una clientela en la Real Cancillería con el propósito de aumentar su peso político en Granada en oposición al Capitán General $^{57}$. Por su futura relación con las hijas del marqués, parece más que probable que Pisa perteneciese también a la clientela de Cenete. Es, a su vez sospechosa, su ya mencionada relación con el conde de Ureña en 1513, debido a las tensiones entre su levantisco hijo Pedro Girón, uno de los amigos del marqués de Cenete, y el conde de Tendilla, brazo armado del rey, en el enfrentamiento por la herencia del ducado de Medina Sidonia que tuvo lugar por estos años ${ }^{58}$. Más tarde, después del alejamiento de Cenete de la ciudad, se formó un grupo de oposición alrededor de Luis Fernández de Córdoba, duque de Sessa, en cuyo matrimonio Pisa había prestado sus servicios como abogado. Acerca de este grupo de oposición Luis Hurtado de Mendoza escribió en 1522 las siguientes líneas a Carlos V:

el marqués del Zenete se quiso poner aquí en alguna manera de competençia con mi padre. Y después el duque de Sessa hizo lo mismo conmygo. [...] Las personas que entonçes se juntaron con estos syempre me tienen mala voluntad $[\ldots]^{59}$.

Sin lugar a dudas, Pisa pertenecía de alguna forma al grupo que se había formado con estos dos nobles -aunque no sabemos si se unía a éstos deliberadamente en contra de los Capitanes Generales. Su hijo García de Pisa, no obstante, se encontró en 1556 en el grupo de oposición formado en el Consejo de Granada contra el lugarteniente del Capitán General ${ }^{60}$. El papel que su padre jugó en las luchas por el poder en Granada no está suficientemente claro. Las cartas dirigidas a Pisa en el registro del segundo marqués de Mondéjar no dejan traslucir la verdadera relación entre Pisa y Mondéjar, salvo la ya mencionada carta en la cual Mondéjar alega haber mediado en la Corte el nombramiento de Pisa como regidor. Con razón, Jiménez Estrella toma este testimonio como prueba de que el licenciado de Pisa pertenecía a la clientela del Capitán General ${ }^{61}$. Aun así, parece que en relación al nombramiento de Pisa hubo ciertos problemas: el marqués

57. Galán Sánchez; Peinado Santaella, «Los jueces del rey», p. 286-288.

58. Véase: F. J. Aguado González, «La sucesión en el Ducado de Medina Sidonia a la muerte de don Juan de Guzmán. Conflictos entre el linaje de los Guzmán y el de los TéllezGirón (1507-1517)», Anuario de Estudios Medievales, 19, 1989, p. 689-709, p. 695.

59. Memorial de Luis Hurtado de Mendoza citado por: Jiménez Estrella, Poder, Ejército y Gobierno, p. 291.

60. Jiménez Estrella, Poder, Ejército y Gobierno, p. 139, nota 78.

61. Jiménez Estrella, Poder, Ejército y Gobierno, p. 287 
alega en una carta de finales de octubre de 1516, entonces inmediatamente anterior al nombramiento de Pisa, que «el embarazo que ha avido en lo del licenciado de Pisa no puedo creer que es por otra mano si no por la del licenciado de Vargas» ${ }^{62}$. Otra carta enviada por Mondéjar a Pisa, quien por aquel entonces se encontraba en la Corte en Madrid, demuestra una cierta confianza entre los dos:

Las nuevas que me escrevis de lo que alla pasa os tengo en merced y de mas de tener el buen gusto que todas las cartas son cosa muy de reir para quien no le tocaren y como pueden tocar a todos una vez o otra no se dexan gastar como ellas merecen pues que no os las puedo pagar con escreviros de aca $[\ldots]^{63}$.

La carta termina con un relato sobre la tristeza de la duquesa de Sessa por la muerte del marqués de Priego, que, supuesta la buena relación entre la duquesa y Pisa, debería interesar a este último personalmente. Parece, por lo tanto, que hubo buen entendimiento entre el segundo marqués de Mondéjar, Luis Hurtado de Mendoza, y el licenciado de Pisa durante los primeros ańos de don Luis al frente de la Capitanía general.

Concluyendo, es de suponer, que Pisa, por sus cualidades de abogado, fue una persona requerida por todas las fracciones del poder en Granada y que, aun así, consiguió el buen entendimiento con todos sin comprometerse demasiado con ninguno de los bandos. Parece que, por encima de todos los enfrentamientos, al abogado le interesaba el Derecho y la Justicia, que anteponía al clientelismo interesado, como ya se ha comenttado anteriormente. Esta actitud se dejaba traslucir ya en el enfrentamiento entre la Cancillería y la Capitanía General en 1513 y también se observa en las razones por las que Pisa finalmente abandonó la Corte: finalizado el pleito del marqués del Cenete, que terminó antes de 1531, y por el cual Pisa fue retenido en la Corte, pidió a Carlos V la licencia para volver a Granada y desempeñar otra vez su oficio de Oidor en la Real Cancillería. El presidente Tavera creyó oportuno concederle este deseo, alegando las quejas que había provocado su estancia en la Corte. En el caso de que el marqués de Cenete hubiese pedido a Carlos V una prolongación de la estancia de Pisa en la Corte, deberían de haber nombrado un sustituto del licenciado en la Cancillería ${ }^{64}$. No obstante, Pisa consiguió el permiso para poder regresar

62. Carta del 29. de octubre de 1516. BNE, Registro de cartas, fol. $114 \mathrm{v}$.

63. Carta de Mondéjar a Pisa del 13.2.1517, BNE, Registro de cartas, fol. 143r.

64. «El licenciado de Pisa. Por cedula y mandamiento de su magestad a estado en esta corte 
a Granada, rehusando así a la oferta imperial. No quería tener «placa del consejo» " ${ }^{65}$. Es así como, entre mayo y diciembre de 1532 habría vuelto ya definitivamente a Granada ${ }^{66}$.

Si el propósito de Pisa era retirarse de la Corte para tener menos placa no lo conseguiría con su vuelta a Granada, ya que allí, en 1532, se vería implicado en dos pleitos ante la Real Cancillería. Uno lo interpuso Francisco de Navas contra él por la compra de un horno cerca de la casa de ambos ${ }^{67}$. El otro lo interpusieron Pedro de Alcalá y García Fernández, ambos de Alcalá, por la propiedad de unas casas, solares, huertos y viñas ${ }^{68}$. Es así cómo, el licenciado, como consecuencia de verse implicado en estos pleitos contra habitantes de Granada, sería trasladado a la Real Cancillería de Valladolid:

El ańo pasado [1534] avia S. M. mandado a don Pedro Pacheco, Obispo de Mondoñedo, que visitase la Audiencia de Granada, y S. M. la mandó ver y se determinó en el mes de hebrero deste año [1535] [...]. Al licenciado de Pisa, que era oidor del Audiencia de Granada, le mandó pasar al Audiencia de Valladolid, porque paresció que ansí convenía porque tenía algunos pleitos con naturales de aquella ciudad y otras diferencias ${ }^{69}$.

Sin embargo, el día 7 de enero de 1536 lo encontramos de nuevo en Granada asistiendo al bautismo de Melchor, hijo de Hernando de Luque ${ }^{70}$. El primero de los dos pleitos mencionados nos arroja algo de información sobre los familiares de la casa de Juan Rodríguez de Pisa: su mayordomo

mucho tiempo entendiendo en el pleito de la marquessa de Zenete. Y agora ques sentenciado a hecho sus diligençias dize que se quiere ir a resedir en su officio de la audiencia de Granada y es anssi nescesario que aun de lo passado avido gran murmuracion y en casso quel marques otra cossa suplicare aviendo se lo su magestad de conçeder converna proveer otro oidor en Granada en su lugar. Por que de otra manera non paresceria ya bien ni descargaria la conçiençia Real». Carta del presidente Tavera a Francisco de los Cobos, sin fecha y lugar, RAH, Col. Salazar, 9 - 470, fol. 112v.

65. Genealogía de la Real Academia: RAH, Col. Salazar: 9 - 146 Bis, fol. 177r.

66. RCG, c. 5373, p. 005. Pleito sin foliación. Los datos proceden del interogatorio hecho a Pisa el día 7 de diciembre de 1532 en Granada donde dice que en mayo de 1532 todavía se encontraba en la Corte.

67. RCG, c. 5373, p. 005.

68. RCG, c. 200, p. 001.

69. Pedro Girón, Crónica del emperador Carlos V. Ed.: J. Sánchez Montes, Madrid, 1964, p. 52.

70. M. de Mina, "La familia Pissa. El hecho histórico», Boletín informativo San Juan de Dios, 187, 1994, p. 67-76, p. 69. 
fue Gonzalo de Lorca, cuyo sobrino, un clérigo, fue sirviente de Pisa y se llamaba Jerónimo Maldonado. Otros criados de Pisa fueron un tal Varea y Hernándo Sánchez, de 50 años de edad, que conocía ya desde hacía 26 años a su amo. Pisa, además, presentó como testigos a Alonso Álvarez de Villareal, íntimo amigo de su casa, a Ángel de Navas y a un tal Trillo.

López Nevot supone que sería a consecuencia de este traslado a Valladolid cuando Pisa renunciara a su oficio de regidor a favor de su hijo García, quien aparece por primera vez con este oficio en $1536^{71}$. No sabemos si también tuvo algo que ver con este traslado a Valladolid el hecho de que Pisa pidiera al Emperador poder trasladar un juro perpetuo que tenía en Granada a Salamanca, Zamora o Toro -petición que, finalmente, no le fue concedida $^{72}$. En 1535 consiguió, junto con su mujer, la licencia para fundar dos mayorazgos, uno para su hijo García y otro para su hijo Diego ${ }^{73}$. Se desconocen el lugar y la fecha de la muerte de Pisa. Parece ser que moriría después de 1548, año en el que se publicó la segunda edición de la Curia Pisana ${ }^{74}$.

\section{JUAN RODRÍGUEZ DE PISA HUMANISTA}

Sin lugar a dudas, Juan Rodríguez de Pisa recibió una educación humanista. Debemos de lamentar el desconocimiento que sobre su educación y formación académica tenemos. Nada sabemos sobre sus primeros años, sobre la escuela donde aprendió latín o sobre la universidad donde obtuvo el grado de licenciado. Desconocemos si estuvo en el extranjero, quizás en Bolonia, la universidad más prestigiosa para juristas, para profundizar sus conocimientos jurídicos. De existir, ésta podría haber tenido lugar antes de su primera mención como encargado de la Tesorería General de la Hermandad en 1498 o, aunque menos probable, después de su estancia en la Real Cancillería de Ciudad Real y antes de su aparición en Granada en 1513. De los años que transcurren entre 1501 a 1513 no disponemos de ningún documento sobre Juan Rodríguez de Pisa. Pero a pesar del desconocimiento absoluto que sobre su educación tenemos, lo que sin lugar a dudas sí podemos constatar es su sólida formación humanista, su profundo conocimiento de los clásicos latinos y, sobre todo, su preocupación por la enseńanza.

71. López Nevot, «De Curia Pisana...», p. 481.

72. AGS, C. C., 178-25.

73. En RCG, leg. 9082, p. 001 se encuentra el traslado de la fundación de los mayorazgos en el cual se basa también Vázquez Cano, «Los Pissa», p. 27.

74. López Nevot, "De Curia Pisana...", p. 481. 
En Granada actuaba como un «delegado» en cuestiones educativas del Ayuntamiento. En 1519 el Cabildo le nombró, junto con el doctor Salazar, visitador del Estudio de gramática ${ }^{75}$. Dicha visita la realizaría finalmente sólo, al encontrarse el doctor Salazar ocupado con otros menesteres ${ }^{76}$. Esta visita concluyó de manera satisfactoria ya que el licenciado de Pisa «le hallo [al bachiller Gonzalo Hernández, regente del estudio de gramática] que leia todo lo que hera mandado ${ }^{77}$. No obstante, no se dejaría convencer demasiado por las habilidades del bachiller: si bien estaba contento con sus enseńanzas, solamente le «tiene al dicho bachiller Gonzalo Hernández por ombre de mediana suficiencia para leer gramática e que asy mesmo le tiene por ombre deliberado de buenos costumbres» ${ }^{78}$. Desde el punto de vista de su erudición, el hecho de que pudiera dar a un profesor de letras la calificación de "mediana suficiencia», sólo es explicable si el mismo Juan Rodríguez de Pisa estuviese en posesión, también, de las cualidades humanistas suficientes para poder valorar así a un profesional de las studia humanitatis.

En 1521 Juan Rodríguez de Pisa recibió el encargo del Cabildo de examinar al repetidor del Estudio de Gramática. El bachiller estaba obligado a presentar a un repetidor en el Cabildo, un deber con el que cumplió Gonzalo Hernández el día 19 de febrero de 1521 al presentar a Alonso de Dueñas $^{79}$. Más tarde, el consejo encargó al licenciado Pisa y a Bernaldino de Mendoza, hermano del marqués de Mondéjar, la revisión de los estatutos del estudio ${ }^{80}$.

Cuando en 1508 el Ayuntamiento de Granada estableció las primeras constituciones del Estudio, en el preámbulo, se mencionó a "onbres legados desta facultad» que las habían elaborado ${ }^{81}$. Desconocemos, si ya en 1508 Juan Rodríguez de Pisa pertenecía a los letrados que, en nombre de la ciudad, se encargaban de la enseñanza pública y si, por lo tanto, colaboró

75. AHMG, Actas Capitulares, 4.1.1521: «E que la cibdad ruega e encarga a los señores licenciado de Pisa e el dotor Salazar que besyten el dicho estudio dos o tres veces en el año e ven si el dicho bachiller haz lo que a de hazer». Véase: López Nevot, El Cabildo, p. 302.

76. Pleito de Gonzalo Hernández contra la Ciudad de Granada. Testimonio del doctor Méndez de Salazar. RCG, c. 1044, p. 9, fol. 93v. Véase mi artículo: «El estudio municipal de gramática en Granada a principios del siglo XVI», Chronica Nova, 24, 2008, p. 161-197.

77. Testimonio de Diego de Padilla, veinticuatro de Granada, quien «asy cree que se lo oyo desir al dicho licenciado de pisa», RCG, c. 1044, p. 9, fol. 72r.

78. Testimonio de Juan Rodríguez de Pisa, RCG, C. 1044, p. 9, fol. 83r.

79. AHMG, Actas del Cabildo del 19.2.1521. Debo el hallazgo de esta entrada en las actas capitulares a López Nevot, El Cabildo, p. 302.

80. Actas del Cabildo del 23.2.1523, en: RCG, c. 1044, p. 9, fol. 23v.

81. Actas del Cabildo de la ciudad de Granada, 7.3.1508, en: RCG, c. 1044, p. 9, fol. 32r. 
en dichas constituciones. Nos inclinamos a pensar que sí por dos razones: primero porque en 1523 también sería el encargado, junto con Bernaldino de Mendoza, de reelaborar los estatutos, y, segundo, porque si tenemos en cuenta la breve introducción que precede a las constituciones, en la que se enumeran las razones que motivaron a la ciudad a establecer un estudio, tras analizarlas encontramos en éstas grandes semejanzas con el pensamiento pisano. La primera de las razones aludidas es de claro habitus humanístico, se trata de una declaración del valor de la ciencia, la cual ennoblece al hombre y ni siquiera el oro puede comprarla. Este concepto de las enseñanzas como imprescindible para el hombre, la humanitas como algo que conviene a cualquier hombre y que le hace apto para ser más digno, es una de las principales aportaciones del humanismo ${ }^{82}$. La virtud va a ser la recompensa que se alcanza a través del estudio, la que concede la verdadera nobleza frenta a la nobleza heredada ${ }^{83}$. Este pensamiento lo vemos reflejado no solamente en las constituciones del estudio granadino, sino también en la Curia Pisana. Pisa, cuando habla de la calidad que se requiere para ser regidor rechaza la opinión de que el regidor tiene que ser noble. Más bien hace alusión a la nobleza de la virtud, rechazando la costumbre de excluir a los plebeyos de las regidurías, diciendo que "in hispania consuetudo est in contrarium. Satis erit que sit nobilis moribus et vita honesta [... ]» ${ }^{84}$.

Pisa, en un elogio al Cardenal Tavera, a quien iba dedicada su obra De Curia Pisana, demostró también la alta estima en la que tenía a la cultura. Para alabar al cardenal, mencionó el apoyo y los favores que recibían los doctos y las artes liberales por parte del Cardenal: «Tu precipue bonarum atrium professors faves. Doctos beneficiis et bonoribus profequeris» ${ }^{85}$. Además de su preocupación por la enseñanza, Juan Rodríguez de Pisa demostró también una gran afición y un profundo conocimiento de la Antigüedad Clásica y de su principal difusor a principios del siglo XVI, el humanismo italiano. En la Curia Pisana cita a autores clásicos como Aulo Gelio, Plutarco, Suetonio, Tácito, Valerio Máximo, y Cicerón. De los humanistas italianos cita a Marco Antonio Sabellico, Angelo Poliziano, Francisco Filelfo, Rafael Maffei Volaterrano. Además, cita a Cardenal Cayetano, Gómez Manrique, Isidoro de Sevilla, y Guillermo Budeo. Un dato llamativo, quizás relacionado con su formación

82. Dice Robert Black, «Humanism succeeded because it persuaded Italian and ultimately European society that without its lessons no one was fit for rule or lead». R. Black, Humanism, The Cambridge Medieval History, vol. 7, Cambridge 1998, p. 244-277, p. 276.

83. P. A. Kristeller, Humanismus und Renaissance. Die antiken und mittelalterlichen Quellen, vol. 2. München 1980, p. 61-62.

84. Pisa, De Curia Pisana, fol. 14r.

85. Pisa, De Curia Pisana, dedicatoria al Cardenal Tavera, fol. 3v. 
humanista es el encargo que el licenciado de Pisa haría al pintor y arquitecto renacentista, Pedro Machuca para el retablo de su capilla en el convento de la Victoria ${ }^{86}$. En un pleito se menciona como testigo de Francisco de Navas al pintor Pedro de Salamanca ${ }^{87}$. ¿ Trabajó acaso también dicho pintor para Pisa? Podría tratarse del entallador Pedro de Salamanca, de quien hace mención Manuel Gómez Moreno, que fue contratado para realizar las estrías y los capiteles de las columnas en la edificación de la Catedral granadina ${ }^{88}$. Finalmente, Pisa es también traductor de uno de los más celebres filósofos del humanismo italiano: Giovanni Pico de la Mirandola.

\section{EL JURISTA}

El método que empleó Pisa en la Curia Pisana es casuístico: «los epígrafes que encabezan los capítulos aparecen formulados de forma interrogativa, a modo de quaestiones que el autor resuelve a partir de la alegación de opiniones doctrinales y textos normativos que va intercalando en el texto, aunque apelando, también, a su propia experiencia personal ${ }^{89}$. Cabe estructurar un poco más el procedimiento de Pisa en su tratado. Una vez planteado el problema, Pisa recurre a cuatro autoridades para solucionarlo. En un primer plano, Pisa recurre a las leyes, tanto al derecho romano, presentado a través de los principales comentaristas y glosadores prehumanistas, como a las leyes del Reino, presentadas a través de las ordenanzas y pragmáticas o Partidas. En un segundo plano recurre a las costumbres. Éstas, al igual que en el plano legal, se estructuran en dos facetas. La primera es la experiencia actual, que es la propia de Pisa en las instituciones del reino, sobre todo en el cabildo granadino, y la segunda, es la experiencia histórica, basada en las costumbres de la antigüedad romana transmitida por la historiografía. Para justificar la importancia de estas costumbres, Pisa afirma: «Et ut nibil antiquitatis ignoretur est sciendum» ${ }^{90}$.

En una ocasión, citará el Epistolarum latinarum de Budé, aunque debemos tener en cuenta que el conocimiento de una edición de uno de los principales representantes del humanismo jurídico no hace de Pisa un

86. M. Gómez Moreno, Las águilas del Renacimiento español: Bartolomé Ordóñez, Diego Silóe, Pedro Machuca, Alfonso Berruguete, 1517-1558, reproducción de la edición Madrid 1941, Madrid, 1983, p. 102.

87. RCG, c. 5373, p. 005.

88. Gómez Moreno, Las águilas del Renacimiento español, p. 75.

89. López Nevot, "De Curia Pisana...», p. 485.

90. Pisa, De Curia Pisana, fol. 17r. 
jurista filólogo. Pisa seguía la mos italicus. Aun así, aceptaba algunas de las principales aportaciones que los humanistas quatrocentistas hicieron al derecho. La primera influencia humanista que el tratado de Pisa deja traslucir es el ya mencionado interés por la historia y la tendencia a explicar las leyes e instituciones romanas en su marco histórico. La segunda aportación humanística se refiere al interés por la filología y la búsqueda del origen y significado exacto de las palabras que Pisa emplea en su tratado ${ }^{91}$. Un buen ejemplo es su búsqueda del verdadero significado de los «decuriones romanos» y los «patres conscripti». Diserta largamente sobre el segundo de los términos, pasando por las autoridades de Sabélico, Volaterrano, Plutarco, Francisco Filelfo y Angelo Poliziano para llegar a la conclusión de que «ego ex predictis quid eligam nescio». Al no poder solucionar el problema, recurre también a los juristas medievales Accursio, Luccas de Penna y a la costumbre del reino castellano ${ }^{92}$. Otro ejemplo donde podemos observar el interés mostrado por Pisa por el origen y significado exacto de un término jurídico es el de los «jurados», a los que relaciona con los antiguos tribunos plebeyos ${ }^{93}$.

Pisa se basa sobre todo en las obras de humanistas que, por su reconstrucción de las instituciones romanas, eran de gran importancia para el mundo jurídico, como las Enneades del humanista italiano Marco Antonio Sabellico, los Commentarii urbani de Raffaele Maffei Volaterrano y el epistolario de Angel Poliziano, donde el humanista italiano disertaba también sobre problemas jurídicos ${ }^{94}$. No obstante, Pisa pertenecía a la tradición jurídica anterior al humanismo filológico representado por Budé, Alciato y Zesio. Éstos introducirán un notable cambio en la interpretación del derecho romano: el punto de partida, según Budé, no deberían ser las interpretaciones y adaptaciones medievales del derecho romano sino su interpretación a base de la historiografía, filología y literatura clásica ${ }^{95}$. Pisa recibió su formación a finales del siglo XV, en un ambiente todavía distinto. El método que había aprendido era la mos italicus. No criticaba sus fuentes con conocimientos filológicos ni criticaba la tradición medieval del derecho romano, aunque aceptó las aportaciones de los humanistas y sabía explorarlas para su tratado.

91. Sobre el humanismo jurídico véase D. Maffei, Gli inizi dell'umanesimo giuridico, Milán 1965, p. 83; A. García García, «Nebrija y el mundo del derecho», Antonio de Nebrija. Edad Media y Renacimiento. Eds.: C. Codoñer; J. A. González Iglesias, Salamanca 1994, p. 121128, p. 126-127.

92. Pisa, De Curia Pisana, fols. 11v-13v.

93. Pisa, De Curia Pisana, fols. 39v-40v.

94. Maffei, Gli inizi dell'umanesimo giuridico, p. 88-93 y 112.

95. David O. McNeil, Guillaume Budé, Ginebra, 1975, p. 22-24. 


\section{LA CONVICCiÓN POLÍTICA DE PISA}

El tratamiento de los problemas expuestos en la Curia Pisana permite extraer algunas conclusiones sobre el pensamiento político de Juan Rodríguez de Pisa. El letrado granadino tiene una idea bien clara de cómo y con quién regir una ciudad. Para justificar sus ideas políticas emplea con gran habilidad las autoridades jurídicas, históricas, las costumbres y su experiencia personal. Ninguna autoridad es intocable si contradice las pretensiones de Pisa. Un ejemplo de esto lo tenemos en el tratamiento de la pregunta sobre cuál había de ser el orden en el que debían sentarse los regidores, y quién de ellos, por lo tanto, ostentaba más nobleza y dignidad. Este problema causaba mucha discordia en los cabildos. Pisa opta por una norma pragmática: el que más tiempo lleve en el cabildo debe ser el primero en el orden. Aquí Pisa contradice a la costumbre, porque dice que «et hoc est servandum etiam si consuetudo esset in contrarium», porque estas costumbres nutren solamente escándalos y pecados ${ }^{96}$. El significado de esta medida tiene un gran peso político. El que más tiempo lleve en el cabildo ostenta también la mayor dignidad. Por lo tanto postula la igualdad entre los regidores. Ni la nobleza ni el peso político deciden sobre el rango de los regidores, sino simplemente la neutral e igualitaria experiencia en el cargo. Hay más indicios de esta convicción «democrática» de Pisa. En otro lugar dice, aduciendo a Tito Livio y Plinio, que, aunque la sabiduría no se reparte en partes iguales entre todos los regidores, el voto de todos ellos sí es igual: «Nam sit impar prudentia par omnia ius est» ${ }^{97}$. Las cualidades que se requieren para la regiduría son igualmente democráticas. Aunque admite que existe también la opinión de que las regidurías queden reservadas a la nobleza, aduce a que la costumbre, en España, es contraria a esto, siendo suficiente, por lo tanto, ser de noble virtud y llevar una vida honesta ${ }^{98}$.

Pisa se muestra muy crítico con la alta nobleza, algo típico de un funcionario real y letrado, aunque sin acercarse a pensamientos demasiado democráticos. Nunca cuestiona la autoridad real. Al contrario, cuando puede, trabaja como abogado de la autoridad y de la soberanía real. Así remonta, siguiendo a $A b$ urbe condita de Tito Livio, el origen de los regidores castellanos a la mitología romana. La historia de los consejos empieza con la instalación del primer senado por Rómulo. Posteriormente, Roma instalaría consejos en

96. Pisa, De Curia Pisana, fol. 16v.

97. Pisa, De Curia Pisana, fol. 35r.

98. Pisa, De Curia Pisana, fol. 14 r. 
todas las ciudades de su Imperio ${ }^{99}$. Los regidores castellanos actuales eran, para el letrado granadino, los sucesores de los miembros de estos consejos romanos, los decuriones ${ }^{100}$. Siguiendo las líneas argumentativas de Pisa, el origen de los regidores castellanos se encontraría en el senado romano, y éste se remontaría a la voluntad autocrática del fundador de Roma. Haciendo referencia a la Antigüedad, Pisa otorga justificación a la dependencia de los oficios municipales castellanos del rey. Habla de cómo existió una época en la que los consejos se cooptaban, aunque esta práctica ya no se utilizaba en la Castilla del momento, donde la costumbre era que el rey nombrara a los regidores. El único caso en el que el cabildo sí conservaba la libertad de elegir a los oficiales y regidores era cuando por costumbre o por privilegio estaba habilitado para esto ${ }^{101}$. ¿Podría estar pensando en las ciudades italianas?

Aquí, en el caso de la autonomía municipal, Pisa se aparta del ejemplo de la Antigüedad y también del uso que los humanistas italianos de las ciudades-estado hacían de la Historia Antigua. Sabellico, a quién Pisa cita frecuentemente, utilizó la historia en sus escritos jurídicos e historiográficos para justificar y ennoblecer las instituciones y libertades de Venecia. Como argumento utiliza un construido paralelismo entre la fundación de Venecia y la de Roma, con lo que postula que la ciudad de San Marcos era heredera de la Roma Antigua ${ }^{102}$. En la Florencia del siglo XV, se recurría al ejemplo de la Roma Republicana precisamente para ilustrar y justificar la libertad, la autonomía de la ciudad y de su oligarquía frente a las intromisiones externas o pretensiones de algún príncipe ${ }^{103}$. Leonardo Bruni recurrió, en sus escritos históricos y panegíricos, a la República romana, no para reflejar la realidad histórica florentina o sus propias convicciones políticas, sino simplemente para hacer uso de sus escritos como vehículos propagandísticos para justificar la política florentina de su tiempo ${ }^{104}$.

99. Pisa, De Curia Pisana, fols. 6r-7v.

100. Pisa, De Curia Pisana, fol. 12r.

101. Pisa, De Curia Pisana, 14v-15r.

102. Sobre Sabélico véase: W. J. Bouwsma, Venice and the defence of Republican Liberty. Renaissance Values in the age of the Counter Reformation, Los Angeles, 1968, p. 89-91, F. Tateo, "Marcantonio Sabellico e la svolta del classicismo quattrocentesco", Florence and Venice: Comparisons and Relations. Acts of Two Conferences at Villa I Tatti in 1976-1977, Florencia 1979 , p. $41-59$, p. 46 y del mismo Autor: «Coccio, Marcantonio, detto Marcantonio Sabelico" en $D B I$, vol. 26.

103. Véase: A. Grafton, «Humanism and political theory», The Cambridge history of political thought. 1450-1700. Eds.: J. H. Burns; M. Goldie, Cambridge 1990, p. 9-29, p. 1429 y M. Hörnqvist, "The two myths of civic humanism», Renaissance Civic Humanism. Reappraisals and Reflections. Ed.: J. Hankins, Cambridge 2000, p. 105-142, p. 142.

104. J. Hankins, «Rhetoric, history, and ideology: the civic panegyrics of Leonardo Bruni», 
No obstante, para el caso castellano, Pisa va a rechazar, visiblemente, la realidad republicana de los consejos municipales, tanto la de la Roma Republicana como la de las ciudades-estado italianas contemporáneas. Refiriéndose a la mitología romana y pasando por alto la Roma Republicana e ignorando también las posibilidades que el derecho romano ofrecía para legitimar la autonomía municipal ${ }^{105}$, Pisa se sirve del humanismo para dar justificación y antigüedad al estado de control, desempeñado por la Corona castellana, sobre los regimientos municipales. Su disertación sobre el origen histórico del Senado y de los decuriones citando fuentes clásicas y obras filológicas recuerdan a Budé: el jurista francés, en el debate entre el Parlamento de París y la Corona francesa sobre quien tenía la soberanía en la jurisdicción, se la otorgaba a la corona. Budé rechazó las pretensiones del Parlamento de comparase con el senado romano y obtener así mayor autoridad $^{106}$.

El humanismo podía ser aplicado perfectamente por apologetas de un gobierno monárquico, como Pisa, e igualmente por defensores de un sistema republicano u oligárquico. Los humanistas simplemente escogían la época romana que mejor se correspondiese con sus apologías: la Roma republicana o la Roma imperial, o, en el caso de Pisa, los orígenes mitológicos de Roma. Pisa otorga autoridad a los regidores por la antigüedad de su cargo aunque no utiliza la historia como instrumento para reivindicar su autonomía. El rey era quien históricamente nombraba a los primeros senadores y quien, según las leyes del reino, los nombraba en ese momento.

Ya se ha comentado como Pisa recurre al derecho positivo del reino, a las costumbres antiguas y modernas y a su propia experiencia. Omite preceptos ético-filosóficos, como el bien común, que igualmente hubieran podido servir como base para disertar sobre el origen, la composición o los deberes del consejo. La presencia del bien común en la obra Pisana queda reducida a un plano inferior. Pisa va a proponer que a la entrada de cada cabildo debería ser puesta una inscripción que instara a los regidores a deliberar sobre el bien común de su ciudad. Los ejemplos a los que Pisa alude son, primero Valerio Máximo, de quien obtiene la información "Rome ubi fiebant concilia erant scriptibus versus». Luego cita los versos de Gómez Manrique en pro del bien común que se encontraban en la casa consistorial de Toledo y, finalmente, la inscripción a la entrada del tribunal bolońés, que reproduce versos en el

Renaissance Civic Humanism, p. 143-178.

105. J. M. Blythe, "Civic humanism and medieval political thought», Renaissance Civic Humanism, p. 31-73, p. 55.

106. "Curiam nostram supremam instar esse Senatus romani; invalid to claim: Parlemente resembles roman senate». McNeil, Guillaume Budé, p. 22-23. 
mismo sentido ${ }^{107}$. Pisa no los menciona como una norma a seguir para los miembros del consejo, una máxima por encima de cualquier otra lealtad personal, sino como una posible amonestación a los regidores para que éstos hagan su trabajo pensando en la comunidad y no en sus intereses privados. No obstante, cuando Pisa diserta sobre los temas propios de las deliberaciones concejales, omite cualquier alusión al bien común. Cita a Aulo Gelio, quién en sus Noctes Atticae escribe sobre el Senado romano donde se debía hablar primero sobre cosas divinas y solamente después sobre asuntos humanos y siempre sobre cosas de la res publica ${ }^{108}$.

Acudir a razones de la filosofía moral podría haber sido interpretado en los ańos treinta del siglo XVI como una crítica hacia la monarquía. Las comunidades de Castilla no estaban todavía lo suficientemente lejos como para haber olvidado las alusiones al bien común hechas por los comuneros. Fórmulas "peligrosas» como el Quod omnes tangit y la idea de que solamente una representación de todos los estamentos en un consejo aseguraría que el regimiento encontrara la vía apropiada hacia el bien común, quedan excluidas del texto de Pisa ${ }^{109}$. Pisa probablemente no era comunero. Su texto iba en contra de cualquier pretensión autonómica por parte de las ciudades, modelada en las ciudades italianas y vigente en Castilla ya a lo largo del siglo $\mathrm{XV}$ y, finalmente, en la guerra de las comunidades ${ }^{110}$. Su visión sobre el Consejo debería haberse basado más bien en la supremacía real, la plenitudine potestatis del monarca como persona por encima de la ley positiva. No critica el hecho de que la libre provisión de las regidurías resida en el príncipe y que éste pudiera otorgar dispensiones si algún regidor no cumplía los requisitos exigidos por la ley. Tampoco menciona la responsabilidad de los regidores con respecto al bien común. Es más, si bien proclama que el consejo habla en nombre de toda la comunidad, no deduce de este hecho la exigencia de

107. Pisa, De Curia Pisana, fols. 7v-8r.

108. Pisa, De Curia Pisana, fol. 17 r.

109. Sobre la evolución del discurso de una política de participación representativa en la Castilla del siglo XV véase: A. Rucquoi, «Démocratie ou Monarchie. Le discours politique dans l'université castillane au XVe siècle», Le discours politique au Moyen Âge. Ed. N. Guglielmi; A. Rucquoi, Buenos Aires, 1995, p. 233-255, p. 253-54. La orientación de las Comunidades en el bien común fue expuesto por J. A. Maravall, Las Comunidades de Castilla. Una primera revolución moderna, Madrid, 1963. Del mismo autor también: "La corriente democrática medieval en España y la fórmula 'quod omnes tangit'", Estudios de Historia del Pensamiento Español, segunda edición, ampliada, Madrid, 1973, p. 173-190.

110. J. Castillo Fernández, "Conflictos y protestas populares en el Reino de Granada (1504-1521)", Carlos V. Europeismo y universalidad. IV. Población, economía y sociedad. Ed.: J. L. Castellano Castellano; F. Sánchez-Montes González, Granada 2000, p. 175-209, p. 186. 
que estuviesen representados todos los estamentos en él ${ }^{111}$. Los regidores reciben su cargo por autoridad regia y tienen entre sus manos el poder de hablar en nombre de toda la comunidad municipal. Pero esta comunidad, en cuyo nombre los regidores actúan, no comparte el poder con el regimiento ni puede influir en él.

Pisa, por lo tanto, defiende la soberanía real contra dos posibles corrientes opositoras. Por un lado, contra la nobleza y sus pretensiones de hacerse con el gobierno municipal. Por otro, Pisa defendió la soberanía real contra los que pretendieron dar más autoridad a los consejos y a las representaciones estamentales frente al poder real, como quedó expresado en las ciudades italianas y en el movimiento comunero. Detrás de esta actitud subyace la teoría de la soberanía regia, elaborada a lo largo del siglo XV por letrados, provenientes de las oligarquías urbanas. Éstos apoyaban el absolutismo regio porque, como fieles servidores y favorecedores del derecho real, veían en la extensión del poder real una forma de extender también su propia influencia ${ }^{112}$.

Estas ideas fueron compartidas también por otro destacado jurista de la misma generación de Pisa, Fernando de Rojas. Según Consolación Baranda, la perspectiva antinobiliaria de la Celestina emana de las convicciones legalistas de los letrados, difundidas a finales del siglo XV en las aulas salmantinas donde estudió Rojas: «la justicia es el mejor instrumento [...] para frenar los desmanes que afectan al conjunto de la sociedad». Eran sobre todo los nobles los que solían eludir las normas de la convivencia ciudadana. Los letrados, en contra de esta actitud, favorecieron la renovación legal, impulsada por los Reyes Católicos ${ }^{113}$.

La guerra de las Comunidades, finalmente, puede ser interpretada también como una de las consecuencias de este pensamiento jurídico, como una lucha por la imposición de la autoridad real frente a los intereses particulares de la nobleza. Enfrentados a un gobierno que había asumido un papel legislativo y administrativo sin precedentes bajo Fernando e Isabel, y que después había fracasado desastrosamente en el manejo de sus nuevas responsabilidades, muchos de los legisladores e intelectuales constararon la necesidad de corregir la tendencia de la monarquía hacia la tiranía ${ }^{114}$. Las Cortes de Valladolid

111. Pisa, De Curia Pisana, fol. 28r.

112. J. M. Nieto Soria, «El "poderío real absoluto" de Olmedo (1445) a Ocaña (1469): La monarquía como conflicto», En la España medieval, 21, 1998, p. 159-228, p. 225.

113. C. Baranda, "Cambio social en la Celestina y las ideas jurídico-políticas en la Universidad de Salamanca», El mundo social y cultural de la Celestina. Eds.: I. Arellano; J. M. Usunáriz, Madrid, 2003, p. 9-25, p. 10-15.

114. S. Haliczer, The Comuneros of Castile. The forging of a Revolution, 1475-1521, Madison 
en 1523, donde Pisa estuvo como procurador de Granada, exigían tras la experiencia de las comunidades, un mayor papel para ellos mismos en la vida pública y la exclusión de los grandes del gobierno municipal ${ }^{115}$.

Lo que, con la ayuda de la soberanía regia, pretendían estas oligarquías urbanas, de las que también Pisa era miembro, era perpetuar su control sobre las ciudades, excluyendo de su regimiento a la nobleza y a otros estamentos.

\section{JUAN RODRÍGUEZ DE PISA, TRADUCTOR DE PICO DE LA MIRANDOLA}

\section{V.1 Apuntes sobre la presencia de Pico de la Mirandola en Espańa}

El mero hecho de haber traducido un texto de Pico de la Mirandola, aunque de índole religiosa, demuestra una vez más la familiaridad de Juan Rodríguez de Pisa con el humanismo italiano. El conocimiento del gran filósofo italiano no era algo excepcional en la Espańa de la primera mitad del siglo XVI, no obstante, las obras de Pico tampoco circularon con tanta frecuencia y por supuesto mucho menos que las de Erasmo. La presencia de Pico durante la primera mitad del siglo XVI la podemos constatar, hasta ahora, en cinco bibliotecas privadas españolas y en el inventario de un librero: el 28 de febrero de 1507 recibió el notario Bernad Camps, vecino de Barcelona, libros de Ana Calvo, viuda de Pedro Camps, médico y ciudadano de Catalayud y hermano de Bernad Camps, entre ellos las Opera Pici Mirandule ${ }^{116}$. El marqués de Priego, Pedro Fernández de Córdoba, poseía en 1518 «dos libros de las obras del conde de la Mirandala (sic)» y "otro libro del conde de Mirandala ${ }^{117}$, el marqués del Cenete, Rodrigo de Mendoza, tenía en 1523 las Pici Mirandule opera y ytem opera mirandulani ${ }^{118}$.

1981, p. 144. La misma interpretación se encuentra en: J. B. Owens, «By my absolute royal authority". Justice and the Castilian Commonwealth at the beginning of the first global age, Rochester 2005, p. 110-113.

115. Haliczer, The Comuneros of Castile, p. 222.

116. Doc. 442, n. 9 en: M. J. Pedraza García, Documentos para el estudio de la historia del libro en Zaragoza entre 1501 y 1521, Zaragoza, 1993, p. 442.

117. María Concepción Quintanilla Raso dice que «es difícil determinar qué obras eran; no se advierte una presencia generalizada de este autor en las bibliotecas particulares, $y$, por lo general, cuando aparecen sus obras no se indican títulos». M. C. Quintanilla Raso, «La biblioteca del marqués del Priego (1518)», En la España medieval, 1, 1980, p. 347-383, p. 361 y 376.

118. F. J. Sánchez Cantón, La biblioteca del marqués del Cenete, iniciada por el Cardenal 
Benito Arias Montano en un inventario de los años 1548 y 1553 incluía las Opera omnia entre sus libros ${ }^{119}$. En Barcelona constan el 27 de febrero de 1527 las Opera Picii Mirandulla en la lista de los libros que Joan Bages había vendido de los que en 1524 le había entregado en comisión el librero Joan Trinxer ${ }^{120}$. Hernando Colón tenía también obras de Pico de la Mirandola y compró sus Opera omnia en 1512 en Roma ${ }^{121}$. Otro dato destacable sobre la difusión de la obra de Pico de la Mirandola es la presencia de un «tractatus contra conclusiones picos dela mirando[la]» en un inventario anónimo del año 1504. Este tratado no ha podido ser identificado, pero Carmen Albert y María Fernández de la Vega suponen que se trata de una contestación a la obra Conclusiones Philosophicae Cabalisticae et Theologicae del Pico ${ }^{122}$. Supongo que se trata de las «Determinationes magistrales contra conclusiones apologales Joanis Pici Mirandulani», de Pedro García, miembro de la comisión nombrada por Inocencio VIII para deliberar sobre las conclusiones de Pico ${ }^{123}$. Es notable el hecho de que ya en 1504 se discutiesen las Conclusiones de Pico de una forma tan intensa en Castilla que provocaran una contestación. Para comparar los datos sobre la presencia de obras de Pico en España con los de otros países, donde en fecha temprana también circularon las obras de Pico, tenemos el caso de Inglaterra, donde constan cinco inventarios de bibliotecas que hasta 1537 contenían obras de Pico ${ }^{124}$. Un número comparable al existente en el contexto español.

Un factor importante para la difusión de las obras de Giovanni Pico de la Mirandola deberían haber sido las ediciones de las opera del filósofo italiano a partir de 1496. La primera edición, de Bolonia de 1496, se encuentra, según el Patrimonio Bibliográfico Español, siete veces en España. La edición de Venecia de 1498 cuenta igualmente con siete libros en bibliotecas españolas, la de Estrasburgo de 1504 con cinco, una edición de ¿Regio? de 1506 cuenta

Mendoza (1470-1523), Madrid, 1942, p. 51 y 73.

119. A. Rodríguez Moñino, "La biblioteca de Benito Arias Montano. Noticias y documentos para se reconstrucción (1548-1598)", Revista del centro de estudios extremeños, 2, 1928, p. 555-598.

120. J. M. Madurell Marimón; J. Rubió y Balaguer, Documentos para la historia de la imprenta y la librería en Barcelona (1474-1553), Barcelona, 1955, p. 687.

121. Colón compró la edición de 1506 impresa por Ludovicus de Mazalis. Véase: Catálogo Colectivo del Patrimonio Bibliográfico Español.

122. A. Carmen; M. Fernández Vega: Un inventario anónimo en Castilla la nueva: 14941506, Madrid, 2003, p. 111.

123. Roma: Eucharium Silber, 1489.

124. G. B. Parks, «Pico della Mirandola in Tudor Translation», Philosophy and Humanism. Renaissance Essays in Honor of Paul Oskar Kristeller. Ed.: Edward P. Mahoney, Leiden, 1976, p. 352-369, p. 353. 
con dos libros, la de París de 1517 con diez y la de Venecia de 1519 otra vez con $\operatorname{dos}^{125}$.

La presencia de Pico de la Mirandola en el pensamiento pedagógico y filosófico español de la época, aparentemente debería buscarse en las repercusiones que dejó su Oratio que se haría famosa posteriormente con el título un poco erróneo Discurso sobre la dignidad del hombre. Francisco Rico recogió varios testimonios de la «dignidad del hombre» en el ámbito académico español en la primera mitad del siglo XVI. Según Francisco Rico:

la obra del Conde della Mirandola gozó en España una difusión inmensa (y en más de un sentido extraordinariamente reveladora). Y si -a mi propósito actual- cabe debatir la realidad de su influjo en Luis Vives o en Fernán Pérez de Oliva, en otros casos no existe duda posible ${ }^{126}$.

Algunos de los casos que demuestran el indudable influjo de la Oratio de Pico, posteriores a los de Vives y Pérez de Oliva, son los de Lope Alonso de Herrera, Juan Pérez, Cervantes de Salazar, Pedro Malón de Chaide y Francesc Décio. ${ }^{127}$ Por lo tanto, parece que en el tercer decenio del siglo XVI el pensamiento filosófico de Pico de la Mirandola, tal como lo había expresado en su famoso discurso, había entrado ya de lleno en el mundo académico hispánico. Pero ¿qué pasa con los indicios sobre la presencia de la dignidad humana en España anteriores a esta fecha?

Hernán Pérez de Oliva (1494-1533), autor de un Diálogo de la dignidad del hombre ${ }^{128}$, podría haber conocido el discurso de Pico tanto en las universidades de Alcalá o Salamanca, como en el extranjero, en la universidad de París o en la de Roma ${ }^{129}$. Probablemente fue también en París -allí Lefèvre d'Etaples fue uno de los principales propulsores de Pico de la Mirandola-

125. Catálogo Colectivo del Patrimonio Bibliográfico Español.

126. F. Rico, El pequeño mundo del hombre. Varia fortuna de una idea en las letras españolas, nueva edición corregida y aumentada, Barcelona, 2005, p. 113.

127. F. Rico, «Laudes litterarum: Humanismo y dignidad del hombre en la España del Renacimiento", Homenaje a Julio Caro Baroja. Ed.: A. Carreira; J. A. Cid; M. Gutiérrez Esteve; R. Rubio, Madrid, 1978, p. 895-914, p. 904 y 908-911; Francisco Rico, El pequeño mundo del hombre, p. 113.

128. Sobre la cuestión de la influencia del discurso de Pico sobre el de Pérez de Oliva véase F. Pérez de Oliva, Diálogo de la dignidad del hombre. Ed.: M. L. Cerrón Puga, Madrid, 1982, p. 23, nota 13.

129. A. Capitán Díaz, «Estudios de humanidad y la dignidad del hombre», Revista Española de Pedagogía, 45, 1987, p. 459-499, p. 462-464. 
donde otro español, Juan Luis Vives, conoció el pensamiento del filósofo italiano. Un posible testimonio del influjo de Pico de la Mirandola nos lo brinda su Fabula de homine (1518) ${ }^{130}$. Otro testimonio temprano donde cabe debatir el influjo directo de Pico es la Oratio con la que Guillén de Brocar inauguró el curso académico en Alcalá de Henares ya en el otoño de 1520. Esta Oratio, quizás sin reflejar las ideas de Pico y basándose en Nebrija y Valla, defendía el valor de las studia humanitatis dignas para el hombre libre ${ }^{131}$.

Francisco Rico se pregunta si «no están actuando unos mismos fermentos culturales» tanto en Pico como en Vives y Pérez de Oliva (a los que también podríamos añadir Brocar) ${ }^{132}$. El tema de la dignitas hominis bebe de fuentes mucho más profundas y Pico, aunque quizás es el más influyente, no es el único ni el más temprano representante de este pensamiento en el Renacimiento ${ }^{133}$. Este hecho podría explicar también que Ottavio Di Camillo detectase influencias del tema de la dignidad humana ya en la Celestina ${ }^{134}$. Hablar de una influencia directa de la Oratio de Pico en fechas tan tempranas no es del todo imposible, aunque sí poco probable, si tenemos en cuenta que la influencia directa de la Oratio debería haber tardado un poco hasta hacerse sentir en España. Como dice Eugenio Garin, la Oratio de Pico se divulgó sobre todo después de la muerte de su autor a partir de la primera edición de las Opera omnia de $1496^{135}$.

Además del tema de la dignidad humana, la Oratio de Pico de la Mirandola divulgó también otros temas, entre ellos, tendría también una gran repercusión el de la teología platónica. Aquí cabe constatar lo mismo que con el tema de la dignidad humana: éste podría haberse difundo igualmente sin el conocimiento directo de la obra de Pico, sobre todo si se tiene en cuenta el impacto que causó el magisterio de Ficino en Italia y la presencia de sus obras en las bibliotecas españolas. Un ejemplo de esto nos lo brinda el poema Las cosas de menos pruevas de Juan Boscán, escrito antes de 1514 y publicado por primera vez en el Cancionero general de Valencia en

130. C. G. Noreña, Juan Luis Vives, La Haya, 1970, p. 62 y 63 n. 54.

131. Rico, «Laudes litterarum...», p. 895-898.

132. Rico, Pequeño mundo, p. 103.

133. Sobre esta cuestión véase H.-U. Musloff, Erziehung und Bildung in der Renaissance. Von Vergerio bis Montaigne, Köln, 1997, p. 46-48.

134. O. Di Camillo, «Ética humanistíca y libertinaje», Humanismo y literatura en tiempos de Juan del Encina. Ed.: J. Guijarro Ceballos, Salamanca, 1999, p. 69-82, p. 80.

135. Giovanni Pico della Mirandola, De dignitate hominis. Ed.: Eugenio Garin, Berlin, 1986, p. 7. 
$1514^{136}$, donde se observan ciertas semejanzas con la Oratio de Pico. En el texto se imbrican platonismo, mitología clásica y cristianismo, combinando la teología platónica y la cristiana, de acuerdo con las propuestas de Pico sobre los misterios de las religiones ${ }^{137}$. No obstante, Antonio Armisén alega que «aceptar como un hecho la influencia directa de la famosa Oratio de Pico de la Mirandola no parece prudente» ${ }^{138}$.

Analizar el impacto que causó la obra de Giovanni Pico de la Mirandola en España a través de los temas de la teología platónica y la dignidad humana no es, por lo tanto, un camino exento de peligros. Ambos temas se difundieron sin la influencia de Pico y fueron, finalmente, catalizados cuando se difundió la Oratio del filósofo italiano. Pero jes posible conectar la presencia de ambos temas en torno a 1500 con la recepción directa de los pensamientos de Pico? ¿Cuales y de quién son las primeras citas directas de la obra de Pico de la Mirandola en España?

Los primeros promotores de las ideas de Pico de la Mirandola en España pueden haber sido los profesores salmantinos Aires Barbosa y Antonio de Nebrija ${ }^{139}$. Nebrija, según José Amador de los Ríos, escribió una carta al filósofo italiano. Lamentablemente, al no indicar la fuente consultada para realizar tal declaración, no hemos podido comprobar su veracidad ni el contenido de la carta ${ }^{140}$. La familiaridad de Nebrija con la obra de Pico consta como muy tarde de 1509, cuando Nebrija mencionó a Pico de la Mirandola en su discurso para agradecer al rey el haberle nombrado cronista real, citándole como punto de referencia para humanistas, junto con Angel Policiano y Hermolao Bárbaro ${ }^{141}$. Finalmente, en el prólogo a la Thalichristia de Alvar Gómez de Ciudad Real de 1522, Nebrija dice al lector que aquí tiene «el poema de la Teología, que echaban de menos hace tanto tiempo los varones más eminentes, y pedía con ansias un Conde italiano, Juan Pico

136. H. Keniston, Las treinta of Boscán. An edition printed before his death, New York, 1911, p. 2.

137. A. Armisén, "Alegoría e imitación en las coplas de Boscán "Las cosas de menos pruevas"», BBMP, 59, 1983, p. 79-140, p. 93 y 127-28.

138. Armisén, «Alegoría e imitación...», p. 85.

139. En los inventarios antiguos de la universidad salmantina de principios del siglo XVI no se encuentran las obras de Pico de la Mirandola. No obstante, se hallan muchos ejemplares de las ediciones tempranas de las obras del filósofo italiano en la actual biblioteca universitaria. Un ejemplar de la edición de Venecia de 1496 y otro de la de 1498, un ejemplar de la edición de Estrasburgo de 1504 y uno de la de Paris de 1517.

140. J. Amador de los Ríos, Historia crítica de la literatura española, vol. 7, edición facsímile de la edición Madrid 1865, Madrid, 1969, p. 202.

141. F. G. Olmeto, Nebrija (1441-1522). Debelador de la barbarie. Comentador eclesiástico. Pedágogo-poeta, Madrid, 1942, p. 192. 
della Mirándula (...)» ${ }^{142}$. Aires Barbosa fue profesor de griego en Salamanca y compañero de Nebrija después de haber estudiado en Bolonia con Ángelo Poliziano $^{143}$. En su edición de la Historia Apostolica de Arator, de 1516, cita la famosa Oratio de Pico de la Mirandola ${ }^{144}$.

Alvar Gómez de Villareal, estudiante en Alcalá, se dejó, influir por la idea de la teología poética de Pico de la Mirandola para escribir su Thalichristia ${ }^{145}$. Entre sus escritos se encuentra también una página con apuntes sobre Pico de la Mirandola, donde cita, entre otras, una epístola de Pico a Marsilio Ficino en la que el italiano habla sobre sus estudios del árabe, hebreo y caldeo:

postquam [enim] Hebraicaelinguae, perpetuum mensem, dies, noctesque inviguilavisem, ad Arabicae studium et Chaldaicae totus me contuli, nihil in eis veritus me profecturum minus quam in Hebraica profecerim, in qua possum nondum quidem cum laude, sed citra culpam epistolam dictare ${ }^{146}$.

La información sobre los estudios de Pico en hebreo, caldeo y árabe la vemos también repetida en la Mirandulae Vita, del sobrino de Giovanni Pico, Gian Francesco Pico della Mirandola, donde dice que su tío «non modo ex latinorum petitas arculis, graecorumque excerptas scriniis, sed ex Hebraeorum etiam mysteriis erutas, chalderumque arcanis atque Arabum vestigatas» ${ }^{147}$. Resultan llamativas estas dos citas, porque, en su contenido, se parecen al diálogo Breve disputa de 1519, en el que Fernando Alonso de Herrera, profesor en Alcalá y probablemente alumno de Nebrija en Salamanca, habla sobre la estancia de su amigo Hernán Núnez de Toledo en Italia y dice:

142. Cito según Olmeto, Nebrija, p. 59.

143. Con más información bibliográfica véase la entrada «Barbosa, Aires» de Sebastiáo Tavares de Pino en Biblos. Enciclopédia Verbo das Literaturas de Lingua Portuguesa, Lisboa 1995.

144. "Quod deus in se omnia continent: uti omnium principium. Hoc aut omnia continet. Quo fit (ut Picus ait) uti in deo sit omnia meliore nota: quo in se ipsis: In homine: inferiora nobiliori sint conditione. Superiora degeneret [...]». J. V. de Pina Martins, «Giovanni Pico della Mirandola nella cultura portoghese del cinquecento». Giovanni Pico della Mirandola. Convegno internazionale di studi nel cinquecentesimo anniversario della morte (1494-1994), vol. 2. Ed.: G. Carfagnini, Mirandola, 1997, p. 415-450, p. 420 n. 17.

145. Sobre la poesía de Álvar Gómez véase: J. F. Alcina Rovira, «Erasmismo y poesía en España», Erasmus in Hispania Vives in Belgio. Eds.: J. Ijsewijn; A. Losada, Lovania, 1986, p. 197-214, p. 200-203.

146. BNE, Mss 8624, fol. 283. Compárese con la edición de la carta en las Giovanni Pico della Mirandola, Opera omnia, vol. 1, edición facsimile de la edición de Basilea 1557, Hildesheim, 1969, p. 367.

147. Pico della Mirandola, Opera omnia, fol. 3v. 
fue a darse un verde de lo griego, y no a darse a los vicios. Y no contento con estos gastos y trabajos, por parescerse, a quanto yo creo, a Juan Pico de la Mirandula, nueua luz de los letrados, no holgó, con su prestez de ingenio, hasta que se vio docto en lo hebreo, caldeo y arávigo ${ }^{148}$.

En la Breve disputa su autor intenta demostrar, ante todo, la necesidad del dominio de la retórica también en el campo de la filosofía. Quién prescinda de ella, será incapaz de convencer de que su argumento es el mejor, por muy buen filósofo que sea. La lógica queda, en el concepto de Herrera, por lo tanto, como vehículo de la retórica ${ }^{149}$. Pero la Breve disputa trata además el filosófico tema de si las hablas son cantidades o no, tema muy discutido en la época, también por Nebrija, Vives y Erasmo. La interpretación antiaristotélica y anti-escolástica que Bonilla hace de este texto podría, no obstante, ser matizada. María Isabel Lafuente Guantes sostiene que Herrera optó por una postura ambigua: «es claramente anti-aristotélica en su tesis central (las hablas no son cantidades), pero aristotélica en su defensa de la lógica realista frente a la nominalista» ${ }^{150}$. El tema de las categorías y los números fue una cuestión por la que se interesó Pico de la Mirandola, el cual defendería, sobre todo, su pitagórica y platónica interpretación ${ }^{151}$. Para averiguar si Pico influyó en el texto de Herrera y, en tal caso, para averiguar las deudas que Herrera contraería con el italiano, sería necesario un análisis profundo de la Breve disputa con la Conclusio de mathematicis secundum opinionem propiam de Pico, cosa que no cabe en el presente artículo.

Hernán Núñez de Toledo, al que Herrera comparó con Pico de la Mirandola por su conocimiento de idiomas, estuvo en torno a 1500 dos veces en Italia, donde entre otras cosas se dedicaba al estudio del griego. Su profesor era, entre otros, Filippo Beroaldo, amigo de Pico. Probablemente en Granada aprendió árabe, caldeo y hebreo. Sería raro que un hombre con tal formación, alumno de un profesor que era amigo de Pico, con tales

148. Hernando Alonso de Herrera, "Breve disputa de ocho levadas contra Aristótil y sus secuaces. Ed.: Adolfo Bonilla y San Martín", Revue Hispanique, 50, 1920, p. 61-196, p. 154. Cito por la nueva edición de esta obra: Hernando Alonso de Herrera, La Disputa contra Aristóteles y sus seguidores. Ed.: M. I. Lafuente Guantes; M. A. Sánchez Manzano, León, 2004, p. 221.

149. Bonilla y San Martín (ed.), Alonso de Herrera, «Breve Disputa...», p. 84.

150. Lafuente Guantes (ed.), Alonso de Herrera. La Disputa contra Aristóteles, p. 108.

151. L. Valcke, "Giovanni Pico della Mirandola e il ritorno ad Aristotele», Giovanni Pico della Mirandola. Convegno internazionale di studi nel cinquantesimo anniversario della morte (1494-1994). Ed.: G. C. Carfagnini; L. S. Olschki 1997, p. 327-349, p. 332-334; Bonilla y San Martín (ed.), Herrera. «Breve disputa...», p. 93. 
intereses y tal conocimiento del humanismo italiano no hubiera conocido la obra de Pico de la Mirandola durante su estancia en Italia. Pico fue estimado por sus contemporáneos entre otras cosas por su conocimiento de idiomas, sobre todo el hebreo ${ }^{152}$. Sería, por lo tanto, poco probable que el ejemplo de Pico no hubiera influido a Hernán Núñez en su plan de estudios, como dijo ya Herrera ${ }^{153}$.

Las citas de Pico empleadas por los humanistas españoles demuestran que, a lo largo de los primeros dos decenios del siglo XVI, Pico de la Mirandola se había convertido para los los humanistas espańoles en toda una autoridad científica. Las citas de Barbosa, Nebrija, Gómez de Villareal y Herrera ofrecen, además, un indicio sobre los temas tratados tras la primera recepción de Pico. No serán ni el de las laudes litterarum ni tampoco el de la dignitas hominis, temas con los que, más tarde, sería identificado el nombre de Pico. Se trataba de temas diferentes, aunque también contenidos en su Oratio: la poesía teológica (Nebrija, Gómez de Villareal), la unidad de la sabiduría (Barbosa), y, sobre todo, la filología (Herrera, Núñez de Toledo) con los esfuerzos realizados por Pico sobre de las lenguas hebrea, caldea y árabe.

Concluyendo, cabe constatar que la obra de Pico de la Mirandola cuenta con una buena presencia en las bibliotecas privadas espańolas en la primera mitad del siglo XVI. Los primeros testimonios claros sobre el conocimiento de escritos del filósofo italiano en España datan del primer decenio del siglo XVI, siendo éstos la cita de Nebrija y la presencia de un tratado contra Pico en una biblioteca anónima. No obstante, es bastante probable que la obra de Pico de la Mirandola llegara a difundirse en la Península con anterioridad. La presencia de humanistas, formados en Italia, como profesores de

152. S. Gentile, «Pico Filologo», Giovanni Pico della Mirandola. Convegno internazionale, p. 465-490, p. 468-469.

153. Hernán Núńez no cita nunca a Pico de la Mirandola en sus obras. Tampoco tenía una propia edición de sus obras entre sus libros. Pero este indicio, según creo, no es un argumento en contra de la familiaridad de Hernán Núnéz con la obra de Pico de la Mirandola. Primero, como observa J. V. de Pina Martins «I retori i filologi nel XVI secolo non usavano citare i loro contemporanei, preferivano l'autorità della cultura greco-latina». Véase: J. V. de Pina Martins, "Giovanni Pico della Mirandola nella cultura portoghese del cinquecento», Giovanni Pico della Mirandola. Convegno internazionale di studi nel cinquecentesimo anniversario della morte (1494-1994), vol. 2. Ed.: G. C. Carfagnini, Mirandola 1997, p. 415-450, p. 418. Esta observación se puede confirmar también para la obra de Hernán Núñez. Segundo, nuestro conocimiento de la biblioteca del Pinciano todavía es fragmentario y no se puede descartar del todo que poseía también las obras de Pico. Biblioteca y epistolario de Hernán Núñez de Guzmán (El Pinciano). Una aproximación al humanismo español del siglo XVI. Eds. J. Signes Codoñer; C. Codoñer Merino; A. Domingo Malvadi, Madrid, 2001. 
letras a finales del siglo XV en las universidades españolas, hace probable que la obra de Pico de la Mirandola fuese conocida y difundida entre los estudiantes. Un primer centro de difusión pudo haber sido Salamanca, con los profesores Nebrija y Barbosa. Posteriormente, es probable que Alcalá cobrase más importancia donde, a partir del segundo decenio del siglo XVI, se encontraban muchos de los primeros mediadores de la obra de Pico: los profesores Nebrija, Hernando Alonso de Herrera y Hernán Núñez y, más tarde, también, Alvar Gómez de Villareal y el bachiller Pedro de Rua ${ }^{154}$. Hay que mencionar también, el influjo que ejerció la Universidad Parisiense (uno de los primeros centros de recepción de la obra de Pico) ${ }^{155}$ en la vida académica española de principios del siglo XVI (piénsese en Pérez de Oliva o en Vives, formados en parte allí, y de gran repercusión en la península). Con las Opera de 1496 se encontraba, además, al alcance de la comunidad científica, una edición de las obras de Pico que pudo haber jugado un papel importante en su difusión.

Las Regulae Duodecim partim excitans partim dirigentes hominem in pugna spirituali de Pico de la Mirandola fueron publicadas por primera vez en las Opera de la edición bolońesa de 1496 y van a estar incluidas en todas las ediciones posteriores de las obras y letras de Pico ${ }^{156}$. Lo más probable es que Pisa conociera tal opúsculo a través de la edición de 1496 o en una edición posterior de las Opera. Pero ¿dónde y cómo se puso en contacto con la obra de Pico de la Mirandola? Si estudió a finales del siglo XV en Salamanca, podría haber conocido directamente allí la obra del filósofo italiano. Otra posibilidad es que la hubiese conocido durante una posible estancia en Bolonia. Podemos constatar ciertas coincidencias que, si bien pueden ser fruto de la casualidad, no obstante, me gustaría mencionar, y es que Giovanni Pico de la Mirandola se puso en contacto con los estudios hebraicos y sobre todo con la Cábala en Florencia a través de Yehiel da Pisa, en cuya casa vivió durante siete años. Los Pisa de Florencia eran una familia de banqueros judíos que jugaron un papel muy importante en la vida cultural florentina del siglo $\mathrm{XV}^{157}$. Sería aventurado suponer una relación entre los Pisa españoles y los Pisa italianos ya que el apellido puede ser pura coincidencia. No obstante, en

154. Sobre Pedro de Rua véase abajo punto 5.2.

155. A. Renaudet, Préréforme et Humanisme à Paris pendant les premières guerres d'Italie, $2^{a}$ edición, corregida, de la edición Paris 1953, Ginebra, 1981, p. 158.

156. D. Maskell, «Robert Gaguin and Thomas More, translators of Pico della Mirandola», Bibliothèque d'Humanisme et Renaissance, 37, 1975, p. 63-68, p. 63 n. 1.

157. B. C. Novak, "Giovanni Pico della Mirandola and Jochanan Alemanno», Journal of the Warburg and Courtauld Institutes, 45, 1982, p. 125-147, p. 126. 
el caso de que sí hubiese alguna relación familiar entre las dos familias, cabría suponer que Juan Rodríguez, durante su estancia en Italia, se hubiese puesto en contacto con ellos, en cuya casa hubiera podido conocer sin problema la obra del filósofo italiano.

Todavía cabe una tercera y última posibilidad siendo quizás ésta la más probable. Si suponemos que Pisa se encontraba en Granada a partir de 1504, cuando la Real Cancillería fue trasladada a la ciudad nazarí, podría haber conocido allí a alguno de los humanistas españoles que, probablemente, ya en fecha temprana conocían la obra de Pico de la Mirandola como Hernán Núnez de Toledo, quien, por aquel entonces, trabajaba como preceptor en la Alhambra de los hijos del conde de Tendilla, y, quien, aparte, desempeñó, entre 1502 y 1512 el oficio de regidor en sustitución de su padre cuando éste se encontraba ausente ${ }^{158}$. No tenemos indicios de que Juan Rodríguez de Pisa y Hernán Núñez de Guzmán, se conocieran, aunque resulta bastante probable. Los dos pertenecían a la misma generación, desempeñaban funciones administrativas en Granada y tenían intereses culturales comunes. Si Hernán Núñez regresó de un viaje italiano a Granada, probablemente con conocimientos sobre las últimas novedades de las studia humanitatis, podría haber puesto a Pisa en contacto con la obra de Pico de la Mirandola.

¿Podríamos considerar a Granada junto a Salamanca como un primer centro de difusión de las obras de Pico de la Mirandola? He podido encontrar cinco tempranos testimonios sobre la presencia de Pico de la Mirandola en España que, de alguna forma, están relacionados con el ambiente intelectual granadino. En primer lugar el de Juan Rodríguez de Pisa; en segundo lugar el de Hernando Alonso de Herrera, quien mencionaría al filósofo italiano en su cita sobre Hernán Núnez. Herrera se encontraba en Granada hasta aproximadamente el año 1501 donde perteneció a la órbita del primer arzobispo granadino, Hernando de Talavera, y a la de Ińigo López de Mendoza, primer marqués de Mondéjar ${ }^{159}$. Su hijo, Lope Alonso, brillaría posteriormente con un discurso sobre la dignidad humana con alusiones a Pico de la Mirandola ${ }^{160}$. Tampoco hay que olvidar que Nebrija, ya en fecha temprana, cuando estuvo al servicio de Juan de Zúńiga, estaba ya en contacto con Hernán Núñez ${ }^{161}$. Finalemente, hay que mencionar la presencia de las

158. A. Domingo Malvadi, «La correspondencia del Pinciano», Biblioteca y epistolario de Hernán Núñez de Guzmán, p. 219-378, p. 233-236.

159. Bonilla y San Martín (ed.), "Alonso de Herrera, Breve Disputa...», p. 64.

160. Bonilla y San Martín (ed.), "Alonso de Herrera, Breve Disputa...", p. 68-71.

161. Hernán Núńez menciona en sus glosas al Laberinto de fortuna de Juan de Mena un paseo nocturno con Nebrija «viniendo de Alcántara a Villanueva de la Serena, caminando 
obras de Pico en las bibliotecas de Cenete, Priego y de Mondéjar. Tanto el marqués del Cenete como el marqués de Priego y el marqués de Mondéjar tuvieron relaciones con Italia. El marqués del Cenete estuvo, personalmente, a principios del siglo XVI en Italia y tuvo, por lo tanto, la ocasión de comprar allí libros del filósofo italiano. Pedro Fernández de Córdoba no viajó nunca a Italia, pero se servía de agentes italianos y de su tío, el Gran Capitán, quienes le mandaban libros desde Italia ${ }^{162}$. La presencia de Pico en la biblioteca de los Mondéjar en el inventario de 1580 puede deducirse probablemente de la adquisición de este libro por el primer marqués, Ińigo López, o por el segundo, Luis Hurtado ya que ambos mantenían contactos no solamente con el humanismo peninsular sino también con el europeo ${ }^{163}$.

Los contactos de estos tres nobles con Italia nos ofrecen una explicación plausible sobre su conocimiento de la obra de Pico de la Mirandola. Juan Rodríguez de Pisa mantuvo relaciones con los tres. Pertenecía, como ya se ha mencionado anteriormente, a la clientela del marqués del Cenete. Asimismo, estaba también relacionado con la familia de los Fernández de Córdoba y ya se ha aludido a su relación con los duques de Sessa. Desconocemos si Pisa entró en contacto con el marqués de Priego, algo que resultaría bastante probable pero que, por la falta de testimonios, entraría ya en el campo la pura especulación. También he hecho ya mención a la relación entre Pisa y el primer y segundo marqués de Mondéjar. Resumiendo lo expuesto, la obra de Pico de la Mirandola se introdujo en Granada -quizás a través de Hernán Núñez de Guzmán, Juan Rodríguez de Pisa o algún noble culto- donde se estaba difundiendo entre los círculos intelectualmente más avanzados, entre nobles, juristas y humanistas ${ }^{164}$.

una noche con agua [...]». Hernán Núñez de Toledo, Las CCC del famosíssimo poeta Juan de Mena con glosa, Granada 1505, fol. 83r.

162. Sobre las bibliotecas de Cenete y Priego véanse los ya citados artículos de Qintanilla Raso y Sánchez Cantón.

163. Sobre el primer marqués de Mondéjar véanse: J. M. Martín García, Iñigo López de Mendoza. El conde de Tendilla, Granada 2003; sobre el segundo marqués, Luis Hurtado de Mendoza, véase: Emilio Meneses García, «Luis Hurtado de Mendoza», Hispania, 36, 1976, p. 526-565 y del mismo autor: «Luis Hurtado de Mendoza, marqués de Mondéjar (1525-1566)», Cuadernos de la Alhambra, 18, 1982, p. 143-177. Sobre la biblioteca de los Mendozas granadinos existe un inventario de 1580 en la Sección Nobleza del Archivo Histórico Nacional, Osuna, C. 291, D. 12. En el inventario de 1580 de la biblioteca de los Mendozas granadinos se encontraron dos obras de Pico de la Mirandola, editadas en 1502, las Disputationum adversus astrologos, Deventer: R. Pafraet, 1502 o el Opus epistolarum, Amberes: Thierry Martens, 1502. Actualmente estoy preparando una publicación de este inventario.

164. Cabe mencionar la presencia de las obras de Pico de la Mirandola en dos bibliotecas granadinas de la segunda mitad del siglo XVI. Además de la ya mencionada biblioteca de los Mendoza (1580), se encuentran en la biblioteca del licenciado Tomás de Villanueva (inventario 


\section{V.2 Las Doce Reglas en la traducción de Juan Rodríguez de Pisa}

Las Doce Reglas de Pico de la Mirandola es un texto puramente espiritual, cuyo propósito es ayudar al hombre en la lucha por la militia christi, como se dice en el título. A menudo se ha visto en este opúsculo de Pico un claro testimonio del influjo de Giovanni Savonarola sobre el filósofo italiano. Heinrich Reinhardt, no obstante, supone que el rigorismo ético, expresado en las Doce Reglas, puede tener como fuente, no solamente a Savonarola, sino más bien a Cicerón y a otros representantes de la filosofía estoica, y sobre todo a San Pablo y sus amonestaciones por la imitatio christi. Las Doce Reglas, entre otras obras religiosas de Pico, transmiten un mensaje no ya filosófico, sino puramente místico: el hombre, miembro de la militia christi, está inmerso en una constante y penosa batalla espiritual contra el pecado y, solamente la mediación de la pasión de Cristo y su imitación con la cruz como supremo símbolo de esta imitatio christi, consigue salir victorioso frente a la militia diabolit ${ }^{165}$.

¿Por qué tradujo Juan Rodríguez de Pisa las Doce Reglas de Pico de la Mirandola? Pisa disponía de una amplia y profunda formación humanista. Por eso, a primera vista, resulta sorprendente que el jurista español tradujera precisamente esta obra del italiano. Las Doce Reglas eran una de las obras de Pico de la Mirandola, que ya desde fechas muy tempranas, contaron con traducciones al francés y al inglés, realizadas por estudiosos de gran renombre. Existen dos versiones en francés dedicadas al rey Enrique VII, la primera anónima y la segunda hecha por el estudiante Henry Hault ${ }^{166}$. Acaso sea Tomás Moro, el traductor más famoso del opúsculo de Pico de la Mirandola, quién ya en torno a 1504-05, tradujo las Doce Reglas al inglés, convirtiendo la prosa del texto original en versos. El humanista inglés conoció la obra de Pico de la Mirandola seguramente por mediación de su amigo John Colet o por otro conocido suyo, el banquero italiano Antonio Bonvyse de Lucca ${ }^{167}$. Más tarde, en 1534, Thomas Elyot, amigo de Tomás Moro, publicó una

de 1567). María A. Moreno Trujillo, «Griego, Latín, Hebreo y otras artes: La librería de un erudito humanista en Granada», Tomás Quesada Quesada. Homenaje, p. 759-789.

165. H. Reinhardt, Freiheit zu Gott. Der Grundgedanke des Systematikers Giovanni Pico della Mirandola (1463-1494), Ratisbona 1986, p.145 y n. 390. Sobre la metáfora de la batalla en Pico, Doce Reglas, véase F. E. Zapatka, "Prose Apothegms into Rime Royal: Thomas More's Translation of Pico della Mirandola's "Twelve Rules"”, Acta Conventus NeoLatini Guelpherbytana. Proceedings of the Sixth International Congress of Neo-Latin Studies. Ed.: S. P. Revard; F. Rädle; M. A. Di Cesare, Binghamton, 1988, p. 395-400, p. 396.

166. G. B. Parks, «Pico della Mirandola in Tudor Translation», p. 354-355.

167. W. E. Campbell (Ed.), The english works of Sir Thomas More, vol. 1, London, 1931, p. 18-19. 
nueva traducción de las Doce Reglas ${ }^{168}$. En el ámbito alemán serían editadas ya en 1500 por Jacob Wimpfeling en Estrasburgo y en 1507 por Johannes Murmellius ${ }^{169}$. En España, la traducción de Juan Rodríguez de Pisa no es el único testimonio del interés que despertaron las amonestaciones de Pico. En los apuntes manuscritos del bachiller Pedro de Rua se encuentra, entre las traducciones de dos cartas de Pico a su sobrino, una traducción de las Doce Reglas al castellano. Esta traducción, aunque contemporánea a la de Pisa, es totalmente independiente no detectándose ninguna dependencia entre los $\operatorname{textos}^{170}$.

La traducción de Juan Rodríguez de Pisa es bastante fidedigna. Solamente en la décima regla la traducción es un poco más libre, ańadiendo expresiones explicativas, pero sin cambiar el contenido: donde Pico decía: Ut in tentationibus semper in principio ocurras, et allidas paruulos Babylonis ad petram. Petra aut est Christus: quia sero medicina paratur, Pisa dice: «en las tentaciones socorras en el principio y despeñes los niños que son los pensamientos en la peña que es Jesu Christo que si los dexas crecer verna tarde la medicina» ${ }^{171}$. Los "paruulos Babylonis» significan para la exégesis tradicional, según San Jerónimo, los orígenes o las primeras nociones de un posible pecado que nos susurra el tentador. Pico empleó este motivo en el sentido tradicional y tras él, también Erasmo ${ }^{172}$. Pisa, no obstante, borra la palabra Babylonia, quizás para hacer la lectura más fácil, o, quizás no conocía el bíblico origen del motivo.

Juan Rodríguez de Pisa podría haberse sentido atraído por el texto espiritual por varias razones. Si partimos de las circunstancias personales del autor, es posible que, al igual que Tomás Moro, Pisa sintiese la tensión entre sus amplias actividades públicas y la necesidad de una devoción y espiritualidad interna. W. E. Campbell supone esto al menos para el humanista inglés, quien se sentía atraído por la obra y la persona de Pico de la Mirandola como reflejo de este conflicto interno al que estaba sometido: "On the one side was the summons to a life of devotion, on the other the claims of humanism and

168. J. M. Major, Sir Thomas Elyot and Renaissance Humanism, Lincoln, 1964, p. $105-107$.

169. Germain Marc'Hadour, "Jean Pic de la Mirandole et son influence au nord des Alpes (1498-1560)». Acta Conventus Neo-Latini Bariensis. Ed.: Rhoda Schnur, Tempe, 1998, pp. 9-24, p. 12.

170. BNE, Mss 7806, fol. 115v-124r. Sobre el bachiller Pedro de Rua, su probable formación académica en Alcalá y su posterior magisterio en Soria véase F. Zamora Lucas; V. Hijes Cuevas, El bachiller Pedro de Rua. Humanista y crítico, Madrid, 1957, p. 12-13.

171. Cito según la ya mencionada edición de Basilea: Opera Omnia, vol. 1, p. 333.

172. Marc'Hadour, «Jean Pic de la Mirandole...», p. 14. 
the active life» ${ }^{173}$. Que Pisa tenía una vida cívica muy activa está demostrado. Pero ¿qué puede haber influido en su evolución espiritual?, ¿Dónde yacen los orígenes históricos de la espiritualidad devocional de Pisa?

Pisa tenía ascendencia conversa, algo que, tradicionalmente, se relaciona con las actitudes místico-intelectuales o con el triunfo del erasmismo en la primera mitad del siglo XVI ${ }^{174}$. Los alumbrados, por ejemplo, se acercaban social y geográficamente mucho a la biografía de Juan Rodríguez de Pisa. Naturales de la región entre Toledo y Alcalá, provenían, al igual que Pisa, de familias conversas de la primera generación postinquisitorial, y eran gente de letras ${ }^{175}$. No obstante es cuestionable si el origen converso pudo influir en una cierta devoción religiosa. Como afirma M. A. Rábade Obrado, en tiempos de los Reyes Católicos los conversos no adoptaron una postura homogénea frente al catolicismo. Existía una pluralidad religiosa y «se podría casi afirmar que existen tantas actitudes religiosas como conversos» ${ }^{176}$. La familia de los Pisa optó, por lo visto, por una conversión sincera. Al padre de Juan Rodríguez, García de Pisa, le fue concedida una habilitación inquisitorial atestiguándole una vida cristiana muy piadosa ${ }^{177}$. Parece, por lo tanto, probable que su hijo Juan Rodríguez fuese educado con cierto ímpetu religioso.

Otra realidad de Juan Rodríguez de Pisa es la del letrado-jurista. La desconfianza hacia el hombre es algo característico de los letrados-juristas. Al igual que Fernando de Rojas, también Juan Rodríguez de Pisa debería haber visto en las leyes la principal herramienta para llevar a los hombres por el camino de la virtud ${ }^{178}$. Como las Doce Reglas de Pico son una especie de libro de leyes para la vida espiritual, erigidas sobre una concepción pesimista del hombre cuya meta era la de salir impune de la batalla que es el símbolo de la vida, puede que el jurista se sintiera atraído por esta concepción legalista de la obra de Pico.

Sus circunstancias personales -el origen converso, su educación cristiana, su profesión legal y una agitada vida pública- explicarían la atracción que el texto devocional de las Doce Reglas ejercía sobre Pisa. Pero, aparte de

173. Campbell, The english works, p. 19.

174. M. Orfali, «El judeoconverso hispano: historia de una mentalidad», Xudeus e Conversos na Historia. Ed.: C. Barros, Santiago de Compostela, 1994, p. 117-134, p. 118.

175. A. Marquéz, Los alumbrados, Salamanca, 1972, p. 143-144.

176. M. Rábade Obradó, «Los judeoconversos en la Corte y en la época de los Reyes Católicos», Espacio, Tiempo y Forma. Seria IV. Historia Moderna, 6, 1993, p. 25-38, p. 28 n. 9 .

177. Proceso por inhabilitación de Juan Rodríguez de Pisa (1549). AHN, Inq, leg. 120, exp. 9. Citado por Parello, «Communication et rite d'institution...», p. 334.

178. Baranda, «Cambio social...», p. 23. 
estas circunstancias personales, encontramos más factores que pudieron haber influido en la traducción de la obra. La traducción, durante la primera mitad del siglo XVI en España, de una obra mística y espiritual, y centrándose en Cristo como ejemplo, conecta al traductor con un amplio campo de influencias. Tras el regreso de París del abad de Montserrat, García Jiménez de Cisneros, en 1496, se extendería en España la Devotio Moderna encontrándose también, a finales de la centuria, las primeras referencias a la Vita Christi de Ludolf de Saxonia ${ }^{179}$. Con la Vita Christi de Ludolf y la Devotio Moderna se difundió un movimiento espiritual en Espańa que propagó la devoción, el ejemplo y la imitación de Cristo. A partir de 1516 se detecta el influjo directo de Erasmo y de su philosofía christi ${ }^{180}$. El éxito de las Vita Christi en el siglo XVI y la propagación del ejemplo de Cristo por los erasmistas y por la Devotio Moderna pudo haber influido en la formación de la religiosidad del propio Juan Rodríguez de Pisa lo que explicaría su interés por las Doce Reglas de Pico.

No obstante, para lograr identificar las corrientes que pudieron haber servido como fuente para la imitatio christi de Juan Rodríguez de Pisa es oportuno retroceder un poco más en el tiempo hasta las raíces españolas que, a finales del siglo XV, prepararon la acogida y la recepción de la Devotio Moderna, del erasmismo -y, probablemente, también de las Doce Reglas de Pico de la Mirandola. La imagen de Cristo fue propagada ya a finales del siglo XV en poemas religiosos de Montesino, San Pedro, Román, o Iñigo de Mendoza, cuya fuente se encontraba, según la hipótesis de Keith Whinnom, en la reforma franciscana ${ }^{181}$. Ésta influyó en el aumento de la producción de textos que propagaban el ejemplo de Cristo.

Un temprano y muy influyente testimonio de una Vita Christi es la que el primer arzobispo granadino, fray Hernando de Talavera, tradujo del original catalán de la pluma de Eiximenis, y publicó en Granada en $1496^{182}$. Con la ayuda de la imprenta, de sermones y de medidas educativas intentó difundir una religiosidad que se basaba fundamentalmente en Cristo y San Pablo. Talavera, quien como Pisa tenía un origen converso, quería atraer a la población morisca a la Fe Católica, para lo que creyó conveniente recurrir a Cristo y al mensaje de su misionero San Pablo. La influencia de Talavera perduró tras su muerte en el año 1507, saliendo de su casa y

179. K. Whinnom, «The supposed sources of inspiration of spanish fifteenth-century narrative religious verse». Medieval and Renaissance Spanish Literature: Selected Essays by Keith Whinnom. Ed.: A. Deyermond; W. F. Hunter; J. T. Snow, Exeter, 1994, p. 62-96, p. 46-47.

180. M. Bataillon, Erasmo y España, Madrid, 1950, p. 72.

181. Whinnom, «The Supposed Sources of Inspiration...», p. 67.

182. A. G. Hauf: D'Eiximenis a sor Isabel de Villena, Barcelona, 1990, p. 47. 
cabildo algunos de los primeros erasmistas espańoles ${ }^{183}$. Alonso Fernández de Madrid, familiar de Talavera, tradujo el Enchiridion de Erasmo ${ }^{184}$. Este texto emplea el mismo tema que las Doce Reglas de Pico: la militia christi. Si Pisa procedía del mismo círculo que Alonso Fernández de Madrid, no sería nada sorprendente su acogida del opúsculo de Pico. Lamentablemente, en la actualidad, no sabemos si Pisa conoció a Talavera, aunque parece bastante probable. El jurista podría haber entrado en contacto con el fraile jerónimo ya durante la guerra de Granada en la Corte Real, donde Talavera tenía muchos conversos a su servicio. En 1498 Pisa sería enviado, por encargo de la tesorería de la Hermandad, a Granada. Talavera hasta su traslado a Granada en 1492 fue el encargado de llevar los asuntos hacendísticos de la guerra ${ }^{185}$. Quizás se conocieron en 1498 , o incluso ya antes en la Corte, cuando Talavera llevaba todavía los asuntos de la hacienda. Con la llegada de Pisa a Granada igualmente podría haber conocido personalmente a Talavera, si se acepta el año del traslado de la Real Cancillería (1505) como el año de la llegada del jurista a la ciudad nazarí. No obstante, incluso en el caso de que Pisa no lo hubiese conocido personalmente, no cabe ninguna duda de que entró en contacto con las posturas reformistas del primer arzobispo a través de sus discípulos.

\section{Conclusión}

En conclusión, me atrevería a realizar las siguientes hipótesis. En un primer momento, Pisa saldría de su casa habiendo recibido una profunda educación cristiana, con tendencia, quizás, hacia una religiosidad intelectual y mística. Más tarde, durante su formación humanística y jurídica, debió de familiarizarse con las posturas de los filósofos clásicos más populares entre los humanistas españoles: Cicerón y Séneca. De ellos, al igual que Pico de la Mirandola, podría haber aprendido cierto rigorismo ético. Su religiosidad personal, su origen converso y el rigorismo ético de los estoicos le hicieron perfectamente perceptibles una actitud religiosa como la que predicaba y difundía fray Hernando de Talavera, una actitud tolerante (siguiendo a San Pablo) hacia los nuevos conversos y una religiosidad basada en lo ejemplar

183. F. Márquez Villanueva, Investigaciones sobre Juan Álvarez Gato, Madrid, 1960, p. 123-124.

184. Publicado en 1526. Sobre la persona de Alonso Fernández de Madrid véase: L. A. Arroyo Rodríguez, Alonso Fernández de Madrid, Arcediano de Alcor y la "Silva Palentina", Palencia, 1993.

185. Márquez Villanueva, Investigaciones sobre Juan Álvarez Gato, p. 34. 
y lo ético, tomando como ejemplo la vida de Cristo y el rigorismo de San Pablo. Si Pisa, quizás debido a sus contactos con Hernán Núñez y el marqués del Cenete, o tras un viaje a Italia, conoció las obras de Giovanni Pico de la Mirandola, no sería insólito que eligiese las Doce Reglas para traducirlas al castellano. Las Doce Reglas expresan perfectamente los postulados de fray Hernando. Son sencillas amonestaciones para una vida cristiana que se centran en el ejemplo de Cristo.

La traducción al castellano sirvió para la difusión de esta obra. Su forma física es la de una hoja de doble folio impresa en una cara. Parece, por lo tanto, que no sería incluida en una obra mayor sino fabricada para su difusión como carta o panfleto. Palau señala sobre el impreso: «sin indicación tipológica, hacia 1520» ${ }^{186}$. Esto podría situar dicha obra en Granada, donde, por estas fechas, se encontraba Pisa. Si hubiese visto la luz en Granada, cabría pensar que las Doce Reglas seguían el ejemplo de fray Hernando de Talavera, quien no solamente había escrito todas sus obras en castellano, sino que se había servido de la imprenta para su mayor difusión ${ }^{187}$. Lo que realmente importaba a Talavera no era la erudición sino el alcance de sus escritos, y esto más en Granada, donde su Vita Christi y los textos exegéticos fueron publicados, entre otras razones, para instruir a la población morisca granadina en los preceptos de la religión cristiana. Las Doce Reglas de Pico fueron traducidas y enviadas a la imprenta quizás por las mismas razones, para servir como preceptos religiosos a los nuevos conversos. De todos modos resulta más probable su uso por cristianos muy familiarizados con las doctrinas y ritos de la religión en búsqueda de una fe más interior.

Juan Rodríguez de Pisa fue un personaje interesante y típico de la época de los Reyes Católicos y de Carlos V. No solamente por sus obras y su papel de abogado y político, sino, sobre todo, por reunir en su persona unas de las facetas más interesantes y controvertidas de la alta Edad Moderna española: es tanto letrado como converso y humanista y refleja en mayor o menor medida aspectos de cada una de estas tres facetas en su vida. Por último, cabe decir algo sobre la presencia de Pico de la Mirandola en Granada. Según mi parecer, no es nada sorprendente encontrar en Granada uno de los primeros focos para la recepción de la obra de Pico. ¿Dónde si no podrían haber despertado más interés las obras del filósofo italiano con su idea de sintetizar los saberes del mundo greco-romano, hebraico y árabe?

186. A. Palau y Dulcet, Manual del librero hispano-americano, Barcelona, 1948-1977, n. 225231.

187. C. Romero de Lecea, «Hernando de Talavera y el tránsito en Espańa del manuscrito al impreso", Studia Hieronymiana, vol. 1, Madrid, 1973, p. 315-377, p. 361. 


\section{ApÉNDICE}

\section{Estas doze relgas[sic] hizo el conde Pico dela Mirandula. dellas para despertar: y dellas para endereçar los hombres a la pelea espiritual.}

- La primera regla es si al hombre le parecece aspero el camino de la virtud porque continuamente nos conuiene pelear contra la carne: y el diablo: y el mundo. Acuerdese que en qualquier camino que tomare y escogere para buiuir segun el mundo ha de padescer muchas aduersidades: tristezas: daños: y trabajos.

- La segunda regla que: acuerdese el hombre que en las cosas del mundo dura mas la pelea y con mas trabajo y con menos fruto y que trabajo es el fin del trabajo y al cabo pena para siempre.

- La tercera regla que se acuerde que es locura pensar ninguno poder sobir al cielo sino por esta pelea como nuestra cabeça Jesu christo no subio al cielo sino por la cruz: y no ha de ser el sieruo de mejor condicion que el señor.

- La quarta regla: que se acuerde el hombre que no solamente ha de tener por mala esta pelea antes siempre la ha de dessear. aun que otro bien no nos viniesse della sino conformar nos con Jesu christo dios y señor nuestro: y que cada vez que resistiendo a alguna tentacion hazes fuerça a alguno de tus sentidos piensa que te conformas con alguna parte de la cruz de Jesu christo que si resistiendo a la gula affliges el gusto acuerda te del que beuio hiel y vinagre y quando apartares la mano de tomar alguna cosa que te agrada piensa en las manos que por ti fueron enclauadas en la cruz: y si resistes a la soberuia: acuerda te del que siendo dios tomo por ti semejança de sieruo y que se humillo fasta muerte de cruz: y quando te tienda la yra acuerda te de aquel que siendo dios y hombre muy mas justo que todos los hombres como se viesse escarnecer como ladron escupir y açotar y padescer todas las deshonrras: $y$ poner se entre ladrones nunca mostro señal de yra ni de enojo mas padesciendo lo todo respondia a todos muy mansamente: $y$ desta manera si miras todas las cosas de la passion: hallaras que no ay cosa en ella en que no te conformes con Jesu christo.

- La quinta regla que no confies en las doze armas ni en otro remedio humano alguno sino en la virtud sola de Jesu christo que dixo confiad que yo venci al mundo: y en otro lugar el principe deste mundo sera echado del. E desta manera auemos de confiar en su virtud y por ella podremos vencer al mundo y al diablo y por esto siempre auemos de pedir su ayuda por nuestra oracion y por la de sus sanctos.

- La sesta regla que te has de acordar que si venciste vna tentacion que esperes otra por que el diablo siempre rodea a quien trague y assi conuiene seruir siempre en temor y dezir con el propheta mirare sobre mi guarda.

- La septima regla que no te venças del diablo quando te tienta antes le venças a el: y esto sera quando no solamente no te contentes de no pecar: mas de aquella manera donde te tienta tomes ocasion de hazer algun bien como si te representa alguna buena obra para que por alli cayas en vanagloria tu luego pensando que no es obra tuya sino beneficio de dios te humillas y te juzgas poco agradescido a dios de las mercedes que te ha fecho.

- La octaua regla quando peleas lo hagas de manera que venciendo tengas paz para siempre porque puede ser que dios te haga esta merced por su gracia que el diablo 


\section{BULLETIN HISPANIQUE}

no torne a ti enuergonçado como le venciste y despues que le ayas vencido te trates como si luego ouiesses de pelear assi que en la pelea siempre tengas memoria de la victoria y en la victoria te acuerdes de la pelea.

- La .IX. regla avn que te parezca que estas bien armado y aparejado siempre huyas las ocasiones de pecar porque dize el sabio el que busca el peligro perecera en el.

- La .X. regla que en las tentaciones socorras en el principio y despeñes los niños que son los pensamientos en la peña que es Jesu christo que si los dexas crecer verna tarde la medicina.

- La .XI. regla acuerda te que avn que en la lucha de la tentacion te parezca amarga la pelea que es cosa mas dulce vencer la tentacion que hazer el pecado a que te inclina y en esto se engañan muchos que no cotejan la dulçura de la victoria con la dulçura del pecado sino la pelea con el deleyte: y para prueua desto el hombre que mil vezes esperimenta que cosa es dar lugar a la tentacion deuria vna vez prouar que cosa es vencer la tentacion.

- La .XII. regla es si eres tentado no por esso creas que te desampara dios o que no le agradas: o que eres poco justo o perfecto. acuerde se te que despues que sant pablo vido la essencia diuina padescia tentacion de la carne de que dios permitia ser tentado porque no lo fuesse de vanagloria en lo qual el hombre ha de mirar que siendo sant pablo vaso de escogimiento y arrebatado hasta el tercero cielo mas avn estaua en peligro si se ensoberueciesse de sus virtudes y assi lo dize el de si para que la grandeza de las reuelaciones no me ensoberuezca me es dado a guijon de mi carne que me atormenta: y desta causa el hombre principalmente se ha de armar contra la tentacion de soberuia que la rayz de todos los males la soberuia es: contra la qual solo vn remedio ay: pensar siempre que dios se humillo por nosotros fasta la cruz y que la muerte avn que nos pese nos ha de humillar para que seamos manjar de gusanos.

Las doze armas de la pelea espiritual que deuen estar aparejadas quando viene la voluntad de pecar.

- El deleyte breve y poco

- Que le siguen fastio y congoxa

- Perdida de mayor bien

- La vida sueño y sombra

- La muerte aparejada y arrebatada

- Sospecha de no fazer penitencia
- Para siempre el galardon y la pena

- La dignidad y naturaleza del hombre

- La paz que tiene la buena aia

- Los beneficios de dios

- La cruz de Jesu christo

- Lo que hizieron los martyres y los exemplos de los sanctos

Traduzidas de latin en castellano por el licenciado Juan Rodriguez de Pisa. 